This item was submitted to Loughborough's Research Repository by the author.

Items in Figshare are protected by copyright, with all rights reserved, unless otherwise indicated.

\title{
Nocturnal river water temperatures: spatial and temporal variations
}

PLEASE CITE THE PUBLISHED VERSION

http://dx.doi.org/10.1016/j.scitotenv.2014.02.123

\section{PUBLISHER}

(c) Elsevier B.V.

\section{VERSION}

AM (Accepted Manuscript)

\section{PUBLISHER STATEMENT}

This work is made available according to the conditions of the Creative Commons Attribution-NonCommercialNoDerivatives 4.0 International (CC BY-NC-ND 4.0) licence. Full details of this licence are available at: https://creativecommons.org/licenses/by-nc-nd/4.0/

\section{LICENCE}

CC BY-NC-ND 4.0

\section{REPOSITORY RECORD}

Wilby, Robert L., Matthew F. Johnson, and Julia Toone. 2019. "Nocturnal River Water Temperatures: Spatial and Temporal Variations". figshare. https://hdl.handle.net/2134/16258. 
NOTICE: this is the author's version of a work that was accepted for publication in The Science of the Total Environment.

Changes resulting from the publishing process, such as peer review, editing, corrections, structural formatting, and other quality control mechanisms may not be reflected in this document. Changes may have been made to this work since it was submitted for publication. A definitive version was subsequently published in:

Wilby, R.L. Johnson, M.F. and Toone, J.A. 2014. Nocturnal river water temperatures: Spatial and temporal variations. The Science of the Total Environment, 482-483, 157-173. DOI: 10.1016/j.scitotenv.2014.02.123

which has been published in final form at:

http://www.sciencedirect.com/science/article/pii/S0048969714003131

This article may be used for non-commercial purposes in accordance with Elsevier Terms and Conditions for self-archiving. 


\begin{abstract}
Nocturnal water temperature (Tw) affects the behaviour of aquatic biota and metabolism of whole rivers. However, night-time water temperature (nTw) is poorly understood because spot samples are typically taken during daylight hours, or Tw series are aggregated in ways that mask sub-daily properties. This paper examines 15-minute measurements of Tw and air temperature (Ta) collected at 36 sites in the Rivers Dove and Manifold, English Peak District. Data were stratified by day and night then analysed using hysteresis, auto-correlation and logistic regression techniques. Daily hysteresis loops show lagged responses between nTw and previous daylight air temperatures (dTa), plus the influence of groundwater and discharge variations. Logistic regression models were modified using a seasonal factor and explained between 80 to $94 \%$ of the variance in daily maximum nTw; minimum nTw were predicted with less skill, particularly for headwater sites in summer. Downstream variations in model parameters also reflect the influence of groundwater and/or riparian shade, and prevailing weather conditions. A case is presented where an intense summer storm resulted in the propagation of a thermal wave that produced maximum $\mathrm{Tw}$ at some sites during hours of darkness. Hence, our findings show that Tw management by riparian shade has to be seen in a catchment wide context, with anticipated benefits normalised for weather variability, extreme rainfall events, local influence of groundwater, and channel structures.
\end{abstract}

Keywords: Water temperature; logistic regression; hysteresis curve; thermal wave; riparian shade; river management. 


\section{INTRODUCTION}

Ambient water temperature ( $\mathrm{Tw}$ ) regulates the photosynthesis of aquatic plants and the metabolism of cold-blooded piokilotherms, including fish, amphibians and aquatic invertebrates (Berry \& Björkman 1980; Farrell 2009). Extreme Tw can stress or ultimately prove lethal to biota (e.g. Dallas \& Rivers-Moore 2012; Martins et al. 2011) although some fauna can deploy avoidance strategies and/or acclimate to high temperatures (Breau et al. 2011; Cox \& Rutherford, 2000; Geist et al. 2011). Nonetheless, sub-lethal Tw can still impact on spawning and breeding, hatching, growth, behaviour, distribution and phenology, thereby altering population structure and dynamics (Durance and Ormerod, 2007; Thackeray et al. 2010; Ward \& Stanford 1982). There is evidence that Tw is rising in response to climate and environmental drivers, such as land-use change, land-drainage and modification of riparian vegetation (Broadmeadow et al. 2011; Langan et al., 2001; Malcolm et al., 2008; Webb, 1996). Consequently, there have been calls to manage rivers in ways that mitigate temperature increases to 'buy time' for ecosystems to adapt (Hansen et al., 2003; Wilby et al., 2010) whilst achieving other co-benefits (see for example: Nõges et al., 2010).

To date, nocturnal water temperatures (nTw) have received relatively little if any explicit attention (see for example the review of Webb et al. [2008]). This is because spot Tw measurements for compliance monitoring are normally made during daylight working hours (e.g. Orr et al. 2010) or continuous data are summarised as daily means, maxima, minima or ranges (e.g. Cassie et al. 2001; Imholt et al., 2012; Johnson et al. 2013). However, such statistics mask sub-daily variations in Tw that are biologically significant (see below) or misrepresent 'true' Tw through biased sampling. For instance, Everall et al. (2014) show how systematic 15 minute sampling of Tw throughout day and night yields an annual mean Tw estimate for the River Dove that is $\sim{ }^{\circ} \mathrm{C}$ cooler than the mean of monthly spot samples taken only during daylight hours.

Night-time water temperatures influence the behaviour, distribution, refuge use and phenology of cold-blooded organisms (Williams and Boorman, 2012), as well as the metabolism of whole rivers (Demars et al., 2011) (Table 1). For example, timing of feeding in juvenile Atlantic salmon (Salmo salar) depends on Tw, with fish feeding preferentially at night when Tw falls below $10^{\circ} \mathrm{C}$ (Fraser et al. 1993). Furthermore, relatively low nTw may provide relief from higher daytime water temperatures (dTw) in summer or act as a signal in 
the diel activity cycle of some organisms. Nocturnal temperature also affects aeration rates, oxygen saturation levels, and dissolved oxygen concentrations in rivers (Odum, 1956).

Distinguishing between Tw drivers (energy sources) and controls (mechanisms regulating temperature change) is key to understanding the thermal dynamics of river systems (Caissie 2006). Variations in nTw are not well understood compared with dTw. The latter is largely governed by solar radiation, mediated by flow volume, local shading and groundwater inputs (Webb and Walling, 1985). During the day, incoming short-wave radiation is the dominant heat flux; at night heat is lost through long-wave radiation and river bed conduction (Evans et al. 1998; Webb and Zhang 1997). Unfortunately, comprehensive measurement of the energy fluxes and hydromorphological processes governing heat dynamics is seldom undertaken, particularly at the spatial and temporal scales needed to understand (sub-)daily Tw over extended periods (Hannah et al. 2008; Webb and Zhang, 1997).

An alternate to the energy balance approach is to infer Tw from air temperature (Ta) (Erikson and Stefan 2000; Stefan and Preud'homme, 1993; Webb et al. 2003). Both Ta and Tw are forced by solar radiation and weather conditions so $\mathrm{Ta}$ is widely used as a surrogate, (recognising that Ta is not always a useful predictor - for instance when local Ta is strongly influenced by groundwater or artificial heat from urban surfaces and reservoirs). When Ta is the primary predictor of Tw in statistical models, then the coefficients can be assumed to reflect local environmental and catchment controls. For example, previous studies have shown that regression parameters are related to catchment area (Ozaki et al. 2003; Webb et al. 2003), extent of upstream riparian shade and groundwater inputs (Johnson et al. 2013; Toone et al., 2011), baseflow index, percent forest cover and stream order (Chang and Psaris, 2013).

The purpose of this paper is to undertake the first comprehensive assessment of spatial and temporal variations in nTw and then show how a conventional model of dTw can be extended to nTw. We also seek to establish the extent to which riparian shade reduces both dTw and $\mathrm{nTw}$, and the circumstances under which this management option might be less effective. The next section describes our high-density network of paired Ta and Tw measurements, and methods of analysis. This is followed by a description of the temporal and spatial dynamics of Ta-Tw relationships shown by analysis of hysteresis loops and regression model residuals. Finally, we interpret these results from the point of view of nTw modelling and management, in other catchments then close with suggestions for further research. 


\section{FIELD SITES AND METHODOLOGY}

\section{Water temperature network}

The Loughborough University TEmperature Network (LUTEN) consists of 36 sites with paired Ta and Tw monitoring in the rivers Dove and Manifold of the English Peak District (Figure 1). Catchment elevations range from 150 to $450 \mathrm{~m}$, and the dominant land-use in both cases is pasture. The Manifold is mainly underlain by Millstone Grit whereas the Dove flows along then intersects a Carboniferous Limestone outcrop. As a consequence of the contrasting geological context, the Manifold has a dense, dendritic drainage network whereas the Dove has few tributaries but is fed largely by groundwater seepage and surface springs. The sampled lengths from source are 2 to $30 \mathrm{~km}$ in the Dove, and 4 to $18 \mathrm{~km}$ in the Manifold. Bank full channel widths vary between 1.7 to $11.7 \mathrm{~m}$ and 2.9 to $8.5 \mathrm{~m}$ respectively.

Gemini Tinytag Aquatic 2 thermistors were installed at each site, one at the river bed surface in riffles measuring Tw and one approximately $2 \mathrm{~m}$ above the water surface measuring Ta. The instruments log maximum, mean and minimum temperatures every 15-minutes and results are reported here for the two years March 2011 to February 2013. Tinytag sensors have a quoted accuracy of $0.2{ }^{\circ} \mathrm{C}$ which has been confirmed under field and laboratory conditions (Johnson and Wilby, 2013). Sensors were situated in deep environmental shade to minimise the risk of heating by direct solar radiation. Further details of LUTEN, the Dove, and Manifold catchments can be found in Wilby et al. (2012) and Johnson et al. (2013).

Environmental characteristics of reaches between monitoring sites were quantified using field and desk-based techniques. A GIS model was constructed from field survey, aerial photography, a 5 m resolution Digital Elevation Model (DEM) and Ordnance Survey maps. This information was used to quantify the dimensions of the catchment and drainage network. Shading by vegetation was estimated from aerial photographs by calculating the length of river reach between sites that is bordered by narrow $(<10 \mathrm{~m})$ tree cover, either linearly along the bank or via wider (>10 m) bands of broadleaf woodland (Johnson et al., 2013).

Hourly precipitation data were obtained from a UK Met Office station at Leek (ref 30690) which lies $\sim 13 \mathrm{~km}$ to the west of the Dove. Accompanying 15-minute discharge data were obtained from two river gauges maintained by the Environment Agency of England and Wales (EA). The Hollinsclough (HC) gauge has a drainage area of $8 \mathrm{~km}^{2}$ in the upper catchment; the Izaak Walton (IW) gauge is downstream and collects from $83 \mathrm{~km}^{2}$ of the 
Dove (Figure 1). Both discharge records are defined as 'natural to within 10\% at the 95th percentile' by the National River Flow Archive. However, flows in the lower reaches of the Dove (between D17 and D24) are affected by more than 100 shallow weirs and occasional sub-surface field drains.

The Limestone outcrop denotes a zone of substantial groundwater inputs, including several large non-thermal and semi-thermal springs along the Dove (Edmunds, 1971; Abesser and Smedley, 2008). Bi-monthly spot measurements of Tw, conductivity and $\mathrm{pH}$ were taken from surface springs and in the main river channel between springs. Johnson et al. (2013) report that these springs discharge at relatively constant temperatures year-round thereby lowering local Tw in summer but increasing Tw in winter.

\section{Summary statistics and hysteresis loops}

The NOAA solar calculator ${ }^{1}$ was used to classify 15-minute temperature data as either 'day' or 'night' according to sunrise and sunset times based on site latitude and longitude. Daily maximum, mean and minimum temperatures for day and night were then calculated, noting that the number of values in each varies seasonally. The time lag between maximum daily air and water temperatures, and water temperature range during day and night were also derived for each year, month and site. An extreme rainfall event was used to explore downstream propagation and travel velocities of a thermal wave that affected nTw.

Next, temperature series were analysed by constructing hysteresis loops for every day in the two-year monitoring period. Previous studies have used hysteresis loops based on dischargetemperature to diagnose seasonal variations in dominant flow paths (e.g., Subehi et al., 2010). We explore the diel thermal regime (i.e., temperature variation over a 24-hour period) by plotting 15-minute Ta and Tw from 12:00 noon on one day to 11:45 am on the next. The resultant daily hysteresis loop reveals the proportion of time that Tw either lags or leads Ta. Loop dimensions were determined by the diel range of Ta and Tw, and by the time difference between maximum and minimum values (Figure 2).

We are particularly interested in the proportion of time that Ta and Tw were not rising ( $\uparrow$ ) or falling $(\downarrow)$ synchronously (i.e., Ta $\downarrow$ with $\mathrm{Tw} \uparrow$ or Ta $\uparrow$ with $\mathrm{Tw} \downarrow$ ) during either day or night.

\footnotetext{
${ }^{1}$ http://www.esrl.noaa.gov/gmd/grad/solcalc/index.html
} 
Hysteresis may be interpreted as a dynamic lag between cause and effect (here Ta and Tw). During nocturnal clockwise hysteresis (or day-time anti-clockwise hysteresis) Tw rise as Ta falls, signalling advection of warmer water from upstream. Conversely, during nocturnal anticlockwise hysteresis (or day-time clockwise hysteresis) Tw falls as Ta rises, potentially indicating arrival of cooler water affected by net radiant heat loss or snowmelt. Hence, we use hysteresis loops as a tool for detecting conditions under which lagged or de-coupling of Ta-Tw invalidate the assumptions of conventional logistic regression modelling.

\section{Regression analysis}

Predictability of nTw was determined through correlation (with concurrent nTa and lagged $\mathrm{dTa}$ ) then auto-correlation analysis (with lagged $\mathrm{nTw}$ and $\mathrm{dTw}$ ). Separate air-water temperature regression models were then built for day and night using maximum values from each sub-set of the data, noting that maximum nTw nearly always occurs immediately after sunset. Regression models for the Dove were built using Ta at site D11, and for the Manifold site M8 (Figure 1). These Ta series are highly correlated with others in the rest of the network (at least $r=0.97$ ) and have been quality assured with respect to daily values at Buxton meteorological station (Johnson et al. 2013). Data were stratified into two years: March 2011 to February 2012 (Year 1); and March 2012 to February 2013 (Year 2). Regression models were constructed using 22 sites in Year 1, and 12 sites in Year 2. [Note that there are fewer data for Year 2 because high flows in 2012 damaged or dislodged some sensors]. Sites with both years of data were used to cross-validate regression model skill and stationarity.

Logistic regression (rather than linear regression) was used to relate dTw to dTa because this function accounts for freezing and evaporative cooling in the lower and upper asymptotes respectively (Mohensi et al., 1998). The form of the model is:

$$
d T w=\frac{\alpha}{1+\exp ^{\gamma(\beta-d T a)}}
$$

where $\alpha$ is the maximum Tw the model can predict, $\beta$ is the inflection point of the logistic curve, and $\gamma$ is the maximum unit change in dTw per unit change in dTa. The standard model was modified for daily maximum nTw as follows:

$$
n T w=d T w . \delta
$$


where $\delta$ is a seasonally varying factor based on the assumption that over short intervals (less than 24 hours) nTw is highly correlated with preceding maximum dTw (from Eq.1). In other words, dTw provides the initial thermal conditions for subsequent nTw, where the rate of cooling (or warming) is a function of the time elapsed and prevailing weather/river flow conditions. The $\delta$ factor was estimated from the gradient of linear regressions between daily maximum nTw and daily maximum dTw (having stratified data by site, year and season). Although the following analysis focuses on daily maximum nTw we also evaluate $\delta$ scaling for daily minimum nTw using the same approach.

Regression model residuals were tested for autocorrelation using the Durbin-Watson statistic. Residuals for $\mathrm{dTw}$ and nTw models were further analysed with respect to daily discharge. Finally, regression model parameters were correlated with environmental metrics (such as distance downstream, altitude, slope, sinuosity, number of upstream weirs, drainage area, bankfull width and depth, water conductivity, cumulative upstream tree cover, and total time in topographic shade).

\section{RESULTS}

\section{Daily mean and range}

Across all sites and years mean dTw and nTw were $10.0^{\circ} \mathrm{C}$ and $9.8^{\circ} \mathrm{C}$ respectively (Table 2). This is within the accuracy of the thermistors so the difference is actually insignificant. The equivalent values for summer are $13.7^{\circ} \mathrm{C}$ and $13.2^{\circ} \mathrm{C}$, whilst for winter values are $5.3^{\circ} \mathrm{C}$ and $5.6^{\circ} \mathrm{C}$. Hence, on average, water temperatures are marginally lower at night than during the day in summer but warmer at night than during the day in winter. Yet, these summary statistics conceal subtle variations at the site scale. For instance, the difference between day and night water temperatures in the Manifold is greatest at headwater sites (such as M2 and M8 in summer). In the Dove downstream sites (D20 and D23) are cooler at night in summer, and approximately the same temperature as daytime in winter.

Standard deviations of dTw and nTw are lowest at the site with major spring flows (D23) (Table 2). The location of greatest variability is less obvious but was generally at or above D10 during Year 2. The range of nTw and dTw peaks in May-June and is at a minimum in December (Figure 3). Consistent with previous studies, the diel range tends to be greatest at 
upstream sites (Webb and Walling, 1985). This spatial and temporal variability appears to be related weakly to discharge: the largest average temperature ranges in dTw during the summer half year (April to September) tend to be associated with the smallest volumes of water (Figure 4). Conversely, higher discharges in the winter half year (October to March) plus weaker solar forcing tend to dampen diel ranges. Overall, least temperature variability occurs in nTw during winter (Table 2).

\section{Daily extremes}

The time lag between daily maximum air and water temperature also has a spatial and temporal signature. Across all sites the average time difference was 180 minutes in Year 1. However, there is a gradual increase in lag interval with distance downstream in Year 1 that is greatest at D17 (Figure 5). Again, this is consistent with a downstream increase in flow volume and thermal capacity which lead to a slower response to solar heating. The shortest lag times are close to the source (D1) and in the zone affected by spring-flow (D20 to D23). The latter is contrary to expectation and could be due to relatively limited riparian and landscape shade immediately upstream (Johnson et al., 2013). Year 2 had relatively high flows and, therefore, might be expected to have greater mean lag intervals between maximum air and water temperatures. However, the data show an average lag time of 144 minutes in Year 2 compared with 196 minutes for the same sites used in Year 1. Even so, the mean conceals considerable variability in lag interval at each site and the differences between Year 1 and 2 are not statistically significant (Figure 5).

An exceptional rainfall event on 28 June 2012 created an opportunity for more detailed analysis of lagged responses and timing of Tw maxima at different points along the Dove. The rain gauge at Leek indicates that the storm achieved a peak rainfall intensity $>11 \mathrm{~mm} \mathrm{hr}^{-1}$ between 13:00 and 14:00. Water temperatures at D1 (0.4 km from river source) peaked 75 minutes later (Figure 6a), approximately 2.5 hours before the maximum Ta recorded on the same day (Figure 6c). The highest Tw was recorded at D10 (9.6 km from source) where the temperature changed $+3.8^{\circ} \mathrm{C}$ in 2 hours. The thermal wave then propagated and dispersed with distance downstream, arriving at D20 (25.8 km from source) approximately 11 hours later at just after midnight. Hence, maximum nTw at D20 occurred just before minimum nTa (recorded at 01:00 hrs). A similar thermal wave was observed in the Manifold (Figure 6b). 
A plot of lag time (between storm peak and Tw peak) versus distance of site from source shows a gradual deceleration of the thermal wave from initial travel velocities $\sim 1.2 \mathrm{~m} \mathrm{~s}^{-1}$ in the headwaters to $\sim 0.5 \mathrm{~m} \mathrm{~s}^{-1}$ in the lower reaches of the Dove (Figure 6d). Travel times in the Manifold fall on the same curve. [Note that the early peak at D23 and first peak at D20 were excluded from travel time estimates on suspicion that they were generated by rapid runoff from paved surfaces in Milldale and sub-surface field drainage downstream of D22]. This event is significant because it demonstrates that the timing and peak nTw need not always driven by antecedent solar heating. A more systematic investigation of thermal shockwaves revealed that these storm-temperature responses can be generated several times per summer in the Dove (Wilby and Johnson, 2014).

\section{Hysteresis}

Maximum air temperature during the day (dTa) exceeded maximum dTw on $80 \%$ of days during the two-year period (site D11). Conversely, maximum air temperature during the night (nTa) exceeded nTw on only $42 \%$ of days. Hence, nTw is generally warmer than nTa, whereas dTw is generally cooler than dTa. The timing of these maxima and minima broadly define the shape of hysteresis curves (Figure 2). Day-time anti-clockwise or nocturnal clockwise hysteresis can be indicative of heat advection from upstream (as in the case of the 28 June 2012 storm). Under these conditions, Tw rise as Ta falls because Tw is reflecting the advection of warmer water from upstream. Loops can also exhibit mixed behaviours, for example, when Tw lags behind Ta during the day but then leads Ta during the night.

In general, Tw increases with distance downstream because of heat gains from solar radiation (counteracted by discharge accretion, greater thermal capacity and heat loss by conduction). This results in rising and expanding hysteresis loops with distance (Figure 7). In the Dove, a substantial change occurs at D17 where loops contract due to intermittent groundwater inputs. At D23, loop shape changes again as groundwater not only diminishes diel Tw range but also reduces absolute values (Figure 7). The Manifold has limited groundwater seepage so hysteresis shape is more consistent between sites (not shown).

Anti-clockwise hysteresis occurs $63 \%$ of the time in the Dove, and $66 \%$ of the time in the Manifold. This is most notable during periods of low flow but even then there can be temporary reversals associated with cloud cover and/or rainfall (e.g., 7 September 2011 in 
Figure 8). Hysteresis was more frequently anti-clockwise at downstream than upstream sites, particularly in Year 2 when loops were anti-clockwise just 30\% and 42\% of the time in the headwaters of the Dove and Manifold, respectively. On average, anti-clockwise (i.e., lagged) behaviour accounted for a significantly greater proportion of night-time than day time hours (t-test, $p<0.0001$ at all sites). Clockwise loops occur irregularly throughout the monitoring period and are typically associated with periods of higher flow (Figure 9).

\section{Thermal inertia}

The above hysteresis analysis showed that Ta does not always lead Tw. Nonetheless, logistic regression modelling of Tw maxima is conventionally based on Ta maxima recorded within the same 24 hour period, assuming that Ta is a proxy for solar heating. In fact, dTw is strongly correlated ( $r>0.8)$ with dTa occurring up to a week earlier (Figure 10, upper panel). The effect is less pronounced for $\mathrm{nTw}$, for which there is a rapid decay in predictability beyond the preceding dTa (i.e., lag one day). However, nTw was more strongly correlated with lagged dTa during the wetter Year 2; the opposite applied to dTw. Drier conditions in Year 1 favoured higher daytime temperatures and ground heating which exerts significant thermal inertia and influence on dTw (see Webb and Walling, 1992); wetter conditions in Year 2 imply more overcast conditions and reduced heat loss affecting nTw.

Overall, it is evident that nTw is better predicted by lagged dTa than concurrent nTa confirming that river temperatures at night are largely determined by the solar energy flux and heat accumulation from the previous day, as well as the rate at which the water column loses heat via back radiation, sensible heat, conductive transfer and evaporation (Evans et al., 1998). Moreover, both dTw and nTw exhibit significant autocorrelation at all sites except D20 (Figure 10, lower panel) where the thermal regime of the river is a mixture of upstream surface flow, local spring flow and weir effects. In summary, nTw is more strongly correlated with lagged Tw than lagged Ta, supporting the inclusion of the $\delta$ factor in Eq.2 to represent thermal inertia.

Figure 11 shows that the $\delta$ factor for maximum nTw varied between 0.92 (D20, summer Year 2) and 1.03 (D17, winter Year 1 and Year 2). This simple factor explained on average $96 \%$ and $84 \%$ of the variance in maximum nTw (Year 1) for winter and summer respectively. Downstream variations in $\delta$ were greatest during the dry summer conditions of Year 1 and 
appear to reflect presence or absence of springflow and weirs. Conversely, wetter conditions in the summer and winter of Year 2 reduced downstream heterogeneity in $\delta$ and elevated mean values (signalling lower rates of heat loss).

Most marked summer cooling between maximum dTw and nTw occurred at D20 - a site just below a sequence of weirs. Conversely, the greatest winter day to night warming is generally downstream of the semi-thermal springs at D17. Values of $\delta$ greater than 1.0 also arise when the length of day is short in relation to the time-lag between daily maximum Ta and Tw (Figure 5). During winter months Tw maxima often occur after sunset, particularly at the most downstream sites.

The $\delta$ factor for daily minimum nTw was less than 1.0 at all sites in the Dove and least near source (Figure S1). This is because water entering the channel near source at sunrise would not have been subject to direct solar heating. Conversely, water arriving at D20 by sunrise could have been in transit for nearly 12 hours (given the velocities recorded on 28 June 2012). In mid-summer, this packet of water could have been exposed to up to 5 hours of daylight before arriving at the time of minimum nTw.

Due to the larger volume of water (and hence thermal inertia) the correlation between nTw and $\mathrm{dTw}$ would be expected to be greater in winter. This is indeed the case: the $\delta$ factor explained on average $86 \%$ and $46 \%$ of the variance in minimum nTw (Year 1 ) for winter and summer respectively. Overall, predictability was on average lower for minimum nTw than maximum nTw given dTa, and predictability was least for minimum nTw in summer at D2 $\left(r^{2}=0.05\right)$.

\section{Logistic regression modelling}

Logistic regression models were fitted to $\mathrm{dTw}$ and $\mathrm{nTw}$ for each year, using dTa as the predictor in each case. The $\delta$ factor was also used to estimate nTw from modelled dTw (henceforth referred to as the "delta” model). Figure 12 shows the logistic relationships produced by the three models for site D11. Greater variability is evident in observed dTw and $\mathrm{nTw}$ in Year 2. This is reflected by the amount of explained variance which ranges from 94\% for dTw in Year 1 to 83\% for nTw in Year 2. The delta model yields marginally better skill than nTw predicted directly from dTa. Moreover, the delta model is regarded as more robust 
conceptually since the premise of the logistic model (that maximum daytime air temperatures affect maximum daytime water temperatures) and thermal inertia are both respected.

Table 3 shows the explanatory power and standard error of models cross-validated using Year 1 and Year 2 data. All models fit well despite contrasting weather conditions in Year 1 (drought) and Year 2 (the wettest on record in the UK) (Parry et al. 2013). All models fit Year 1 better than or as well as Year 2. However, when calibrated using Year 2, models validate better in Year 1. There is a slight tendency for weaker models in the lower reaches of both rivers that is more evident in the Manifold (Figure S2). Durbin-Watson tests confirm positive, first-order autocorrelation in the residuals of dTw and nTw models. In general, this means that the regression model standard errors and levels of significance reported in Table 3 are inflated.

\section{Analysis of residuals}

Weak seasonality is evident in the residuals of day (not shown) and night models (Figure 13) with consistent under-estimation of summer nTw and over-estimation of winter nTw. This bias is slightly greater for delta models, and much greater for nTw models than for dTw. Models for the Manifold tend to over-predict a greater range of temperatures than those in the Dove. Despite the apparent seasonality in residuals, Ta does not correlate with residuals from any model (i.e., there is no heteroscedasticity).

Visual inspection of Figure 13 suggests that some model residuals (most notably during the wet summer of 2012) may be explained by discharge. However, this is not supported by scatterplots of daily residuals versus daily discharge. Residuals for dTw vary between $\pm 4^{\circ} \mathrm{C}$ regardless of the discharge or site (Figure 14, left column). Residuals for nTw tend to be negative, are generally greater at low flows, and increase in range with distance downstream (Figure 14, right column). For example, the mean residuals from the delta model at D11 for the winter and summer half Year 2 were $+0.24^{\circ} \mathrm{C}$ and $-0.34^{\circ} \mathrm{C}$ respectively.

This implies that the delta model is still missing important information about other energy fluxes and processes that are not captured by dTw alone. For example, under summer low flow conditions under-prediction of nTw might occur when overcast conditions limit cooling by net long-wave radiation; conversely over-prediction might be explained by clear skies at night. Nonetheless, residuals from the delta model exhibit less flow dependence than those 
predicted by dTa, suggesting that heat advection from upstream and flow effects are better resolved by scaling modelled dTw.

\section{Variations in logistic regression parameters}

Logistic regression parameters vary between years and with distance downstream in the Dove but were relatively stable in the Manifold (Figure 15). In the Dove, values of $\alpha$ and $\beta$ were significantly higher in Year 1 than Year 2, whereas the $\gamma$ parameter was lower at most sites. The interplay between these parameters produced more damped responses in high-end dTw in Year 2 for given dTa, probably reflecting the overcast conditions and reduced solar radiation. The effect was most marked at sites with least $(<20 \%)$ riparian shading (such as D1, D17 and D20). In contrast, all sites analysed in the Manifold have greater than 55\% riparian cover so were less responsive to variations in solar forcing.

\section{DISCUSSION}

Temporal and spatial variations in Tw

Temporal and spatial variations in mean dTw and nTw are broadly similar. Maximum nTw is on average 0.4 to $0.5{ }^{\circ} \mathrm{C}$ less than maximum dTw. In the Dove, both $\mathrm{dTw}$ and nTw increase with distance downstream at a rate of $0.07{ }^{\circ} \mathrm{C} \mathrm{km}$-1 between sites D2 and D20. Hence, hysteresis loops generally rise with distance from source except where groundwater inputs substantially alter both the range and absolute values of Tw in the lower Dove (Figure 7). In Year 1, groundwater discharged continuously at site D23 but was intermittent elsewhere only flowing in autumn-winter between sites D16 and D22. In Year 2, extremely wet weather sustained flows from normally intermittent springs and affected Tw downstream of D16. Groundwater not only dampened seasonal variations in Tw, but also reduced the diel range. Hence, dTw and nTw converged when and where groundwater was discharging into the river.

\section{Discharge and lag effects}

Ta responds more rapidly to variations in solar radiation than $\mathrm{Tw}$ and, consequently, $\mathrm{Tw}$ often lags behind Ta, creating anti-clockwise hysteresis in diel temperature under stable, low 
flow conditions (Figure 8). On average, $55 \%$ of diel cycles in the Dove and Manifold exhibit lagged responses. This pattern is more prevalent at night because $\mathrm{nTw}$ is dominated by negative heat fluxes (such as net radiation, sensible heat and conduction), partially controlled by initial water temperature passed from the preceding day.

Local groundwater inputs, high flow episodes and extreme weather can modify this behaviour. For example, some flood pulses can produce a thermal 'shockwave' that is at variance to diel solar radiation because the Tw maximum is experienced during hours of darkness at some sites (as with the storm-temperature response on 28 June 2012, Figure 6). Hence, nocturnal fauna would be impacted first by a thermal wave at a time of day when abrupt Tw increases would not be expected.

Thermal waves have been reported for other upland catchments (e.g., Langan et al., 2001; Subei et al., 2010) and in regulated rivers (Webb, 1995; Toffolon et al., 2011). Summer reservoir releases can cause abrupt temperature increases of $2-3{ }^{\circ} \mathrm{C}$ that persist for tens of kilometres downstream until diminished by tributary inputs, dispersion and heat exchange. Seasonal (clockwise) hysteresis has also been described for diel Tw variations in unregulated rivers. Over this time-scale, solar radiation in spring elevates dTw but not nTw; heat accumulated in the catchment over the summer then maintains both dTw and nTw (reducing the diel range) in autumn (Webb and Walling, 1992).

All models performed better in Year 1 (lower average flows) compared with Year 2 (higher average flows). This is consistent with Webb et al. (2003) who found that linear regression models for Tw had greater explanatory power when discharge was below the median. On average, the lag interval between dTa and dTw is of the order 3 hours but depends on thermal inertia and the velocity of flow through the drainage network. Water body velocity governs exposure time to solar radiation flux as it moves from source to sites downstream. Maximum exposure occurs when a water parcel moves from headwater to outlet during hours of daylight, under low flow conditions with high levels of solar radiation.

In contrast, nTw is indirectly driven by solar heating accumulated by the water body and landscape. Heat is advected downstream but is lost as the night progresses due to the negative heat fluxes noted above. The rate of heat loss is governed by the initial Tw (at sunset), the volume of water (thermal inertia), flow velocity (friction and conduction heat exchanges) and ambient weather conditions (sensible heat flux and net radiation) (Evans et al., 1998). The 
lack of a memory term in the standard logistic regression limits the physical plausibility of the model when applied to nTw.

\section{Variations in regression parameters}

Regression parameters for dTw and the delta factor for nTw differ between sites partly due to environmental and hydrological factors (Figures 11 and 15). It is clear that groundwater strongly affects all regression parameters. In general, $\alpha$ and $\beta$ rise with distance downstream as increased net exposure to solar radiation elevates the maximum attainable Tw, described by $\alpha$. Groundwater discharges at a constant $8.5^{\circ} \mathrm{C}$ in the lower Dove, constraining maximum Tw and hence $\alpha$ and $\beta$ in affected reaches. Groundwater also contributes to variation in regression parameters between years because wet conditions in Year 2 meant that intermittent springs flowed year round. In the Manifold there are no groundwater inputs over the monitored stretch, so variations in $\gamma$ are modest.

Johnson et al. (2013) report a significant correlation between $\gamma$ for daily maximum Tw and cumulative upstream riparian shade. We confirm that $\gamma$ is strongly correlated ( $r=0.82)$ with the same index of shade. However, inter-annual variations in cloud cover (inferred from dryand wet-year comparisons) affected solar radiation receipts and hence the shape of the logistic regression between $\mathrm{dTa}$ and $\mathrm{dTw}$ (Figure S3). For example, when $\mathrm{dTa}=25{ }^{\circ} \mathrm{C}$, the logistic regression model for the unshaded site (D17) predicts maximum dTw of $13.5^{\circ} \mathrm{C}$ (wet year) and $17.9^{\circ} \mathrm{C}$ (dry year). Even at $\mathrm{dTa}=30^{\circ} \mathrm{C}$ the maximum dTw predicted for a wet year is $13.8{ }^{\circ} \mathrm{C}$, well below levels known to harm resident brown trout (Solomon, 2008). As would be expected the greatest benefit of riparian cover occurs under sunny conditions when $\mathrm{dTa}=$ $30{ }^{\circ} \mathrm{C}$ gives maximum dTw of $18.3^{\circ} \mathrm{C}$ (shaded) and $20.4{ }^{\circ} \mathrm{C}$ (unshaded) sites. In this case, the difference in dTw is sufficient to affect trout feeding behaviour (Solomon, 2008).

\section{Stationarity and skill of regression models}

The logistic regression models performed well, with the weakest explaining $80 \%$ of variance (site D23, Year 2 validation, nTw). Models calibrated using the more variable Year 2 conditions performed consistently better in Year 1. Overall, the most problematic sites to model are in zones of intermittent groundwater which buffer against Tw during the winter 
half year, or year round under wet weather. Reaches with no groundwater or constant groundwater performed better, as did sites in Year 2 because otherwise intermittent springs were flowing year-round. When models were cross-validated they performed well despite the dissimilarity in weather conditions. This was regarded as stringent test of the model stationarity and skill.

Furthermore, our results suggest that the basic logistic regression model for $\mathrm{dTw}$ is readily modified for nTw estimation using a seasonal factor $(\delta)$. This simple adaptation works better for daily maxima than minima nTw, and performs better for winter than summer. Again, inter-annual variations in $\delta$ are attributed to the complex inter-play between drivers (net longwave radiation, bed conduction, heat advection from upstream and spring flows) and controls (local shade, pooling by weirs, flow velocity).

\section{CONCLUSIONS}

Water temperatures during hours of darkness are understudied yet can affect the behaviour and well-being of nocturnal biota. Sub-daily, seasonal and inter-annual Ta and Tw variations were investigated using a high-resolution monitoring network in the Dove and Manifold catchments. Hysteresis loops, autocorrelation, regression modelling, and residual analyses were used to explore variations in air-water relationships for daylight and night periods, with the aim of identifying key controls of the sub-daily thermal regime. By statistically modelling day and night water temperatures separately, dTw was confirmed as strongly related to concurrent dTa, but nTw was better explained by lagged dTw than by dTa. Hence, nocturnal water temperatures cannot be understood in isolation of day-time water temperatures.

The influence of dTa on subsequent $\mathrm{nTw}$ is interpreted here as the downstream advection of water heated during preceding daylight hours: the greater the amount of solar radiation during previous days (and months) the higher nTw. This relationship is modulated by discharge and distance downstream. The former controls the thermal heat capacity and rate of advection. The latter determines the range of factors that must be integrated as the water transits from source to site, including mixing of thermally contrasting spring flow. Data from extreme rainfalls in summer 2012 illustrate that abrupt increases in nTw can occur out of synchrony with normal solar forcing of the diel cycle, and are still evident $30 \mathrm{~km}$ from source. 
Groundwater and riparian shade add further complexity to the thermal regime by dampening nTw variations driven by solar forcing. Important considerations are whether the groundwater sources are intermittent or perennial, semi-thermal or cool, surface or sub-surface. Hot/dry/sunny weather conditions maximise the sensitivity of Tw to Ta and the gradient term in dTw regression models is strongly correlated with cumulative upstream riparian shade. Conversely, under cool/wet/cloudy conditions differences in Tw between heavily shaded and partly shaded sites are diminished. Further work is needed to test the generality of these findings in other geological and hydrological settings.

The level of analysis reported in this paper is only possible where there are high resolution temporal and spatial data for Tw. Such data are relatively rare so it is important to draw out transferrable, policy-relevant insights. We identify three headline messages for agencies deploying shade management to retard long-term rises in Tw (see: Nõges et al., 2010; Lenane, 2012).

First, local controls of Tw change should be thoroughly assessed (including potential influence of groundwater, heat advection from upstream, topographic shade, channel orientation and structures, reservoirs thermopeaking, etc.). In other words, site selection for possible tree planting has to be seen in a catchment wide context. Detailed quantitative analysis will clearly be beyond the scope of most agencies, but routine river surveys and fluvial audits could form the basis of qualitative assessment or preliminary site screening. In practice, availability of land and support of land owners will be critical to eventual site choice.

Second, realised benefits of tree-planting will depend on weather variability because the differential between shaded and un-shaded reaches is maximised under hot/sunny conditions when high-end Tw are ameliorated most. Our findings support the view that reducing dTw by shade will likely reduce nTw because of thermal inertia. However, there may be circumstances under which shade offers less protection, as evidenced by storm-temperature responses (and reservoir effects reported elsewhere) which can trigger abrupt changes in nTw. Further research is needed into the source area(s) of the heat in thermal waves in the Dove, and whether there is scope for amelioration by shade management.

Third, the widely used logistic regression model is readily modified to reflect site-specific and time-varying conditions, including estimation of nTw maxima and minima. National Tw archives could be used to estimate logistic regression parameters and relate these to standard catchment properties and hydrological indices. The feasibility of grouping rivers with similar 
Ta-Tw response has already been established for the Dove (Toone et al., 2011) and elsewhere (e.g., Kano et al., 2013).

Finally, the analysis has revealed further opportunities for research. These include the need for a more thorough appraisal of thermal shocks produced by extreme weather events and their associated ecological impacts. The latter may only be feasible to study under the controlled conditions of laboratory experiments. Estimation of nTw minima from Ta remains problematic, particularly for headwaters, yet these may be the preferred locations for riparian tree planting. The search for simple rules that predict Tw model parameters from readily available topographic and remotely sensed data should be a priority. This would enable estimation of the sub-daily thermal regime for ungauged rivers.

\section{ACKNOWLEDGEMENTS}

The authors are grateful to Bruce Webb for his advice and constructive feedback on the manuscript. Positive suggestions from three anonymous reviewers also strengthened the contribution. 


\section{REFERENCES}

Abesser, C. and Smedley, P.L. 2008. Baseline groundwater chemistry: the Carboniferous Limestone aquifer of the Derbyshire Dome. British Geological Survey Open Report, OR/08/028, Keyworth, 64pp.

Baras, E. Seasonal activities of Barbus barbus: effect of temperature on time-budgeting. Journal of Fish Biology 46: 806-818.

Beiswenger, R.E. 1977. Diel patterns of aggregative behaviour in tadpoles of Bufo americanus, in relation to light and temperature. Ecology 58: 98-108.

Berry, J. and Bjorkman, O. (1980) Photosynthetic response and adaptation to temperature in higher plants. Annual Review of Plant Physiology 31: 491-543.

Breau, C., Cunjak, R.A. and Peake, J. 2011. Behaviour during elevated water temperatures: can physiology explain movement of juvenile Atlantic salmon to cool water? Journal of Animal Ecology 80: 844-853.

Broadmeadow, S.B., Jones, J.G., Langford, T.E.L., Shaw, P.J. and Nisbet, T.R. 2011. The influence of riparian shade on lowland stream water temperatures in southern England and their viability for brown trout. River Research and Applications 27: 226-237.

Caissie, D. 2006. The thermal regime of rivers: a review. Freshwater Biology 51: 1389-1406.

Change, H. and Psaris, M. 2013. Local landscape predictors of maximum stream temperature and thermal sensitivity in the Columbia River Basin, USA. Science of the Total Environment, 461-462, 587-600.

Cox, T.J. and Rutherford, C. 2000. Thermal tolerances of two stream invertebrates exposed to diurnally varying temperature. New Zealand Journal of Marine and Freshwater Research 34: $203-208$.

Crawshaw, L.I. 1974. Temperature selection and activity in the crayfish, Orconectes immunis. Journal of Comparative Physiology 95: 315-322.

Demars, B.O.L. and Manson, J.R. 2013. Temperature dependence of stream aeration coefficients and the effect of water turbulence: A critical review. Water Research 47, 1-15. 
Demars, B.O.L., Manson, J.R., Ólafsson, J.S., Gíslason, G.M., Gudmundsdóttir, R., Woodward, G., Reiss, J., Pichler, D.E., Rasmussen, J.J. and Friberg, N. 2011. Temperature and the metabolic balance of streams. Freshwater Biology 56: 1106-1121.

Dou, S., Miller, M.J. and Tsukamoto, K. 2003. Growth, pigmentation and activity of juvenile Japanese eels in relation to temperature and fish size. Journal of Freshwater Biology 63: 152165.

Durance, I. and Ormerod, S.J. 2007. Climate change effects on upland stream macroinvertebrates over a 25-year period. Global Change Biology 13: 942-957.

Edmunds, W.M. 1971. Hydrogeochemistry of groundwaters in the Derbyshire Dome with special reference to trace constituents. Report of the Institute of Geological Sciences, 71/7, British Geological Survey, Keyworth.

Evans, E.C., McGregor, G. and Petts, G.E. 1998. River energy budgets with special reference to river bed processes. Hydrological Processes 12: 575-595.

Erikson, T.R. and Stefan, H.G. 2000. Linear air/water temperature correlations for streams during open water periods. American Society of Civil Engineers, Journal of Hydrologic Engineering 5: 317-321.

Everall, N.C., Johnson, M.F., Wilby, R.L. and Bennett, C.J. 2014. Detecting phenology change in the mayfly Ephemera danica: Responses to spatial and temporal water temperature variations. Ecological Entomology, under review.

Fraser, N.H.C., Metcalfe, N.B. and Thorpe, J.E. 1993. Temperature-dependent switch between diurnal and nocturnal foraging in Salmon. Proceedings of the Royal Society of London B 252: 135-139.

Fraser, N.H.C., Metcalfe, N.B., Heggenes, J. and Thorpe, J.E. 1995. Low summer temperatures cause juvenile salmon to become nocturnal. Canadian Journal of Zoology 73: 446-451.

Geist, D.R., Deng, Z., Mueller, R.P., Brink, S.R. and Chandler, J.A. 2011. Survival and growth of juvenile Snake River fall chinook salmon exposed to constant and fluctuating temperatures. Transactions of the American Fisheries Society 139: 92-107. 
Greenwood, M.F.D. and Metcalfe, N.B. 1998. Minnows become nocturnal at low temperatures. Journal of Fish Biology 53: 25-32.

Gries, G., Whalen, K.G., Juanes, F. and Parrish, D.L. 1997. Nocturnal activity of juvenile Atlantic salmon (Salmo salar) in late summer: evidence of diel activity partitioning. Canadian Journal of Fisheries and Aquatic Science 54: 1408-1413.

Guasch, H., Armengol, J., Marti, E. and Sabater, S. 1998. Diurnal variation in dissolved oxygen and carbon dioxide in two low-order streams. Water Research 32: 1067-1074.

Hannah, D.M., Malcolm, I.A., Soulsby, C. and Youngson, A.F. 2008. A comparison of forest and moorland stream microclimate, heat exchanges and thermal dynamics. Hydrological Processes 22: 919-940.

Hansen L.J., Biringer J.L., Hoffman J.R. (eds.) 2003. Buying time: a user's manual for building resistance and resilience to climate change in natural systems. WWF Climate Change Program, Berlin, Germany, 244pp.

Imholt, C., Soulsby, C., Malcolm, I.A., Hrachowitz, M., Gibbins, C.N., Langan, S. and Tetzlaff, D. 2012. Influence of scale on thermal characteristics in a large montane river basin. River Research and Applications. Early view. DOI: 10.1002/rra.1608.

Johnson, M.F., Wilby, R.L. and Toone, J.A. 2013. Inferring air-water temperature relationships from river and catchment properties. Hydrological Processes early view.

Johnson, M.F. and Wilby, R.L. 2013. Shield or not to shield: Effects of solar radiation on water temperature sensor accuracy. Water 5: 1622-1637.

Johnston, P., Bergeron, N.E. and Dodson, J.J. 2004. Diel activity patterns of juvenile Atlantic salmon in rivers with summer water temperature near the temperature-dependent suppression of diurnal activity. Journal of Fish Biology 65: 1305-1318.

Kano, Y., Vokoun, J.C. and Letcher, B.H. 2013. Paired stream-air temperature measurements reveal fine scale thermal heterogeneity with headwater brook trout stream networks. River Research and Applications doi: 10.1002/rra.2677

Kaplan, L.A. and Bott, T.L. 1989. Diel fluctuations in bacterial activity on streambed substrata during vernal algal blooms: Effects of temperature, water chemistry, and habitat. Limnology and Oceanography 34: 718-733. 
Langan, S.J., Johnston, L., Donaghy, M.J., Youngson, A.F., Hay, D.W. and Soulsby, C. 2001. Variation in river water temperatures in an upland stream over a 30- year period. Science of the Total Environment, 265, 195-2007.

Lenane, R. 2012. Keeping Rivers Cool: Getting ready for climate change by creating riparian shade. Environment Agency, Bristol, 41pp.

Loperfido, J.V., Just, C.L. and Schnoor, J.L. 2009. High-frequency diel dissolved oxygen stream data modeled for variable temperature and scale. Journal of Environmental Engineering 135, 1250-1256.

Malcolm, I.A., Soulsby, C., Hannah, D.M., Bacon, P.J., Youngson, A.F. and Tetzlaff, D. 2008. The influence of riparian woodland on stream temperatures: implications for the performance of juvenile salmonids. Hydrological Processes 22: 968-979.

Martins, E.G., Hinch, S.G., Patterson, D.A., Hague, M.J., Cooke, S.J., Miller, K.M., Lapointe, M.F., English, K.K. and Farrell, A.P. 2011. Effects of river temperature and climate warming on stock-specific survival of adult migrating Fraser River sockeye salmon (Oncorhynchus nerka). Global Change Biology 17: 99-114.

Mohensi, O., Stefan, H.G. and Erickson, T.R. 1998. A nonlinear regression model for weekly stream temperatures. Water Resources Research 34: 2685-2692.

Neal, C., Harrow, M. and Williams, R.J. 1998. Dissolved carbon dioxide and oxygen in the River Thames: Spring-summer 1997. The Science of the Total Environment 210/211: 205217.

Nõges, T., Nõges, P. and Cardoso, A.C. 2010. Review of published climate change adaptation and mitigation measures related with water. Joint Research Centre Scientific and Technical Report EUR 24682 EN. Ispra, Italy, 133pp.

Odum, H.T. 1956. Primary production in flowing waters. Limnology and Oceanography 1: $102-117$.

Oliver, D.R. 1971. Life history of the Chironomidae. Annual Review of Entomology 16: 211230.

Orr, H.G., des Clers, S., Simpson, G.L., Hughes, M., Battarbee, R.W., Cooper, L., Dunbar, M.J., Evans, R., Hannaford, J., Hannah, D.M., Laize, C., Richards, K.S., Watts, G. and Wilby, 
R.L. 2010. Changing water temperatures: a surface water archive for England and Wales. In: Kirby C (ed.) Role of Hydrology in Managing Consequences of a Changing Global Environment. British Hydrological Society.

Ozaki, N., Fukushima, T., Harasawa, H., Kojiri, T., Kawashima, K. and Ono, M. 2003. Statistical analyses on the effects of air temperature fluctuations on river water qualities. Hydrological Processes 17: 2837-2853.

Parry, S., Marsh, T. and Kendon, M. 2013. 2012: from drought to floods in England and Wales. Weather 68: 268-274.

Pinder, A.M., Trayler, K.M., Mercer, J.W., Arena, J. and Davis, J.A. 1993. Diel periodicities of adult emergence of some chironomids (Diptera: Chironomidae) and a mayfly (Ephemeroptera: Caenidae) at a western Australian wetland. Journal of the Australian Entomological Society 32: 129-135.

Riley, A.J. and Dodds, W.K. 2013. Whole-stream metabolism: strategies for measuring and modelling diel trends of dissolved oxygen. Freshwater Science 32: 56-69.

Sjoberg, K. and Danell, K. 1982. Feeding activity of ducks in relation to diel emergence of chironomids. Canadian Journal of Zoology 60: 1383-1387.

Solomon, D.J. 2008. The thermal biology of brown trout and Atlantic salmon: A literature review. Environment Agency, Exeter, 40pp.

Stefan, H.G. and Preud'homme, E.B. 1993. Stream temperature estimation from air temperature. Water Resource Research 29: 27-45.

Subei, L., Fukushima, T., Onda, Y., Mizugaki, S., Gomi, T., Kosugi, K., Hiramatsu, S., Kitahara, H., Kuraji, K. and Terajima, T. 2010. Analysis of stream water temperature changes during rainfall events in forested watersheds. Limnology 11: 115-124.

Teo, S.L.H., Sandstrom, P.T., Chapman, E.D., Null, R.E., Brown, K., Klimley, A.P. and Block, B.A. 2013. Archival and acoustic tags reveal the post-spawning migrations, diving behaviour, and thermal habitat of hatchery-origin Sacramento River steelhead kelts (Oncorhynchus mykiss). Environmental Biology of Fishes 96: 175-187.

Thackeray, S.J., Sparks, T.H., Frederiksen, M., Burthes, S., Bacon, P.J., Bell, J.R., Botham, M.S., Brereton, T.M., Bright, P.W., Carvalho, L., Clutton-Brock, T., Dawsons, A., Edwards, 
M., Elliott, M., Harrington, R., Johns, D., Jones, I.D., Jones, J.T., Leech, D.I., Roy, D.B., Scott, W.A., Smith, M., Smithers, R.I., Winfield, I.J. and Wanless, S. 2010. Trophic level asynchrony in rates of phonological change for marine, freshwater and terrestrial environments. Global Change Biology 16: 3304 - 3313.

Toffolon, M., Siviglia, A. and Zolezzi, G. 2010. Thermal wave dynamics in rivers affected by hydropeaking. Water Resources Research, W08536.

Toone, J.A., Wilby, R.L. and Rice, S. 2011. Surface-water temperature variations and river corridor properties. Water Quality: Current Trends and Expected Climate Change Impacts IAHS Publ. 348: 129-134.

Ward, J.V. and Stanford, J.A. 1982. Thermal responses in the evolutionary ecology of aquatic insects. Annual Review of Entomology 27: 97-117.

Wartinbee, D.C. 1979. Diel emergence patterns of lotic Chironomidae. Freshwater Biology 9: 147-156.

Webb, B.W. 1995. Regulation and thermal regime in a Devon river system. In: Foster, I.D.L., Gurnell, A.M. and Webb, B.W. (Eds) Sediment and Water Quality in River Catchments. John Wiley \& Sons, Chichester.

Webb, B.W. 1996. Trends in stream and river temperature. Hydrological Processes 10: 205226.

Webb, B.W. and Walling, D.E. 1985. Temporal variation of river water temperatures in a Devon river system. Hydrological Sciences Journal 30: 449-464.

Webb, B.W. and Walling, D.E. 1992. Long term water temperature behaviour and trends in a Devon, UK, river system. Hydrological Sciences Journal 37: 567-580.

Webb, B.W., Clack, P.D. and Walling, D.E. 2003. Water-air temperature relationships in a Devon river system and the role of flow. Hydrological Processes 17: 3069-3084.

Webb, B.W., Hannah, D.M., Moore, R.D., Brown, L.E. and Nobilis, F. 2008. Recent advances in stream and river temperature research. Hydrological Processes, 22, 902-918.

Webb, B.W. and Zhang, Y. 1997. Spatial and seasonal variability in the components of the river heat budget. Hydrological Processes 11: 79-101. 
Webb, B.W. and Zhang, Y. 1999. Water temperature and heat budgets in Dorset chalk water courses. Hydrological Processes 13: 309-321.

White, E.M. and Knights, B. 1997. Environmental factors affecting migration of the European eel in the Rivers Severn and Avon, England. Journal of Freshwater Biology 50: 1104-1116.

Wilby, R.L. and Johnson, M.F. 2014. Thermal wave generation and propagation in an upland river. Geophysical Research Letters, in preparation.

Wilby, R.L., Johnson, M.F. and Toone, J.A. 2012. The Loughborough University TEmperature Network (LUTEN): Rationale and analysis of stream temperature variations. Proceedings of Earth Systems Engineering 2012: Systems Engineering for Sustainable Adaptation to Global Change. Newcastle, UK.

Wilby, R.L., Orr, H., Watts, G., Battarbee, R.W., Berry, P.M., Chadd, R., Dugdale, S.J, Dunbar, M.J., Elliott, J.A., Extence, C., Hannah, D.M., Holmes, N., Johnson, A.C., Knights, B., Milner, N.J., Ormerod, S.J., Solomon, D., Timlett, R., Whitehead, P.J. and Wood, P.J. 2010. Evidence needed to manage freshwater ecosystems in a changing climate: turning adaptation principles into practice. Science of the Total Environment 408: 4150-4164.

Williams, R.J. and Boorman, D.B. 2012. Modelling in-stream temperature and dissolved oxygen at sub-daily time steps: An application to the River Kennet, UK. Science of the Total Environment, 423, 104-110.

Willming, M.M., Qin, G. and Maul, J.D. 2013. Effects of environmentally realistic daily temperature variation on pesticide toxicity to aquatic invertebrates. Environmental Toxicology and Chemistry. Early view.

Wojtalik, T.A. and Waters, T.F. 1970. Some effects of heated water on the drift of two species of stream invertebrates. Transactions of the American Fisheries Society 99: 782-788.

Zitek, A., Schmutz, S. and Ploner, A. 2004. Fish drift in a Danube sidearm-system: II. Seasonal and diurnal patterns. Journal of Fish Biology 65: 1339-1357. 


\section{TABLES}

Table 1 Examples of nocturnal temperature effects on biota and river metabolism

\begin{tabular}{|c|c|c|}
\hline Biota & Effect & Source \\
\hline \multirow[t]{5}{*}{ Fish } & $\begin{array}{l}\text { Juvenile Atlantic salmon (Salmo salar) become increasingly } \\
\text { nocturnal foragers as temperatures fall below } 10^{\circ} \mathrm{C} \text {. Fish that are } \\
\text { more active at night are less aggressive, indicating changes in social } \\
\text { structure. }\end{array}$ & $\begin{array}{l}\text { Fraser et al. (1993, } \\
\text { 1995); Gries et al. } \\
\text { (1997); Johnston et } \\
\text { al. (2004) }\end{array}$ \\
\hline & $\begin{array}{l}\text { Minnows (Phoxinus phoxinus) become increasingly nocturnal as Tw } \\
\text { decreases. }\end{array}$ & $\begin{array}{l}\text { Greenwood \& } \\
\text { Metcalfe (1998) }\end{array}$ \\
\hline & $\begin{array}{l}\text { Steelhead salmon (Orcorhynchus mykiss) swim deeper during the day } \\
\text { than during the night. }\end{array}$ & Teo et al. (2013) \\
\hline & $\begin{array}{l}\text { Timing and duration of dusk/dawn activity in barbel (Barbus barbus) } \\
\text { is to achieve thermal homeostasis in a variable environment. Timing } \\
\text { and intensity of drift migration in laval/juvenile cyprinids increases } \\
\text { with Tw. }\end{array}$ & $\begin{array}{l}\text { Baras (2005); Zitek } \\
\text { et al. (2004) }\end{array}$ \\
\hline & $\begin{array}{l}\text { Nocturnal activity of glass eels and elvers (A.japonica) is repressed at } \\
\mathrm{Tw}<15^{\circ} \mathrm{C} \text {. Upstream migration of European eel with maximum } \\
\text { catch at } \mathrm{Tw}>18-20^{\circ} \mathrm{C} \text { and zero catches for } \mathrm{Tw}<10^{\circ} \mathrm{C} \text {. }\end{array}$ & $\begin{array}{l}\text { Dou et al. (2003); } \\
\text { White and Knights } \\
\text { (1997) }\end{array}$ \\
\hline Amphibian & $\begin{array}{l}\text { Tadpoles of the American Toad (Bufo americanus) exhibit diel } \\
\text { activity related to Tw and light gradients. }\end{array}$ & Beiswenger (1977) \\
\hline Crustacean & $\begin{array}{l}\text { The crayfish (Orconectes immunis) selected higher mean } \mathrm{Tw}\left(22^{\circ} \mathrm{C}\right) \\
\text { in experimental conditions when active at night than when inactive } \\
\text { during the day }\left(18^{\circ} \mathrm{C}\right) \text {. }\end{array}$ & Crawshaw (1974) \\
\hline \multirow[t]{4}{*}{ Insect larvae } & $\begin{array}{l}\text { Many insect species (e.g. chironomidae) emerge during daylight in } \\
\text { colder latitudes or cold seasons whereas they emerge at night in } \\
\text { warm latitudes and seasons. }\end{array}$ & $\begin{array}{l}\text { Oliver (1971); } \\
\text { Sjoberg \& Danell } \\
\text { (1982); Pinder et al. } \\
\text { (1993) }\end{array}$ \\
\hline & $\begin{array}{l}\text { Diel pattern of emergence of multiple chironomid species track Tw } \\
\text { fluctuations. }\end{array}$ & Wartinbee (1979) \\
\hline & Diel drift periodicity and amplitude affected by Tw. & $\begin{array}{l}\text { Wojtalik \& Waters } \\
\text { (1970) }\end{array}$ \\
\hline & $\begin{array}{l}\text { Toxicity of agricultural pollutants to aquatic invertebrates is related } \\
\text { to diel temperature variations. }\end{array}$ & $\begin{array}{l}\text { Willming et al. } \\
\text { (2013) }\end{array}$ \\
\hline Algae and bacteria & Activity of bacteria related to diel temperature cycle. & $\begin{array}{l}\text { Kaplan and Bott } \\
(1989)\end{array}$ \\
\hline River metabolism & Effect & Source \\
\hline \multirow[t]{2}{*}{ Dissolved oxygen } & $\begin{array}{l}\text { Temperature-dependent non-linear aeration process increases } \\
\text { nocturnal dissolved oxygen concentrations }\end{array}$ & $\begin{array}{l}\text { Loperfido et al. } \\
\text { (2009); Demars and } \\
\text { Manson (2013) }\end{array}$ \\
\hline & Lower nocturnal temperatures increase oxygen saturation & $\begin{array}{l}\text { Guasch et al. } \\
\text { (1998); Neal et al. } \\
\text { (1998) }\end{array}$ \\
\hline Respiration & $\begin{array}{l}\text { Metabolic rates at night are determined by variations in temperature } \\
\text { and biological activity }\end{array}$ & $\begin{array}{l}\text { Riley and Dodds } \\
\text { (2013) }\end{array}$ \\
\hline
\end{tabular}


Table 2 Annual, summer (June to August) and winter (December to February) mean day and night-time water temperatures at selected sites for Years 1 and 2 of monitoring. The standard deviation (SD) is also given. Missing data are denoted by (-).

\begin{tabular}{|c|c|c|c|c|c|c|c|c|c|c|c|c|}
\hline & \multicolumn{6}{|c|}{ Day } & \multicolumn{6}{|c|}{ Night } \\
\hline & \multicolumn{2}{|c|}{ Annual } & \multicolumn{2}{|c|}{ Summer } & \multicolumn{2}{|c|}{ Winter } & \multicolumn{2}{|c|}{ Annual } & \multicolumn{2}{|c|}{ Summer } & \multicolumn{2}{|c|}{ Winter } \\
\hline & Mean & SD & Mean & SD & Mean & SD & Mean & SD & Mean & SD & Mean & SD \\
\hline \multicolumn{13}{|c|}{ YEAR 1 (drought) } \\
\hline D1 & 9.7 & 2.6 & 11.9 & 0.8 & 5.1 & 1.4 & 9.2 & 2.4 & 11.2 & 0.7 & 5.1 & 1.5 \\
\hline D6 & 11.2 & 2.6 & 13.1 & 1.3 & 6.7 & 1.3 & 10.9 & 2.5 & 12.8 & 1.3 & 6.7 & 1.3 \\
\hline D10 & 10.4 & 3.7 & 14.2 & 1.6 & 5.8 & 1.6 & 10.2 & 3.4 & 13.7 & 1.4 & 5.9 & 1.6 \\
\hline D12 & 10.9 & 3.7 & 14.9 & 1.7 & 6.3 & 1.2 & 10.7 & 3.5 & 14.5 & 1.6 & 6.4 & 1.2 \\
\hline D16 & 10.6 & 3.3 & 14.2 & 1.4 & 6.5 & 1.1 & 10.7 & 3.3 & 14.3 & 1.4 & 6.6 & 1.1 \\
\hline D17 & 10.3 & 3.4 & 14.4 & 1.7 & 6.3 & 1.1 & 10.5 & 3.3 & 14.3 & 1.3 & 6.5 & 1.1 \\
\hline D20 & 11.7 & 4.2 & 16.2 & 1.8 & 6.0 & 1.3 & 11.3 & 3.7 & 14.9 & 1.5 & 6.1 & 1.3 \\
\hline D23 & 9.8 & 2.1 & 11.7 & 0.7 & 7.0 & 1.1 & 9.5 & 1.7 & 11.0 & 0.6 & 7.1 & 1.0 \\
\hline$M 2$ & 10.5 & 4.0 & 14.2 & 1.6 & 4.6 & 2.1 & 9.8 & 3.2 & 12.7 & 1.3 & 5.1 & 1.7 \\
\hline M8 & 11.2 & 4.5 & 15.9 & 1.9 & 5.4 & 1.9 & 10.6 & 4.0 & 14.8 & 1.7 & 5.8 & 1.6 \\
\hline M11 & - & - & - & - & - & - & - & - & - & - & - & - \\
\hline M12 & 11.0 & 4.4 & 15.6 & 1.8 & 5.3 & 2.0 & 10.8 & 4.2 & 15.4 & 1.7 & 5.6 & 1.8 \\
\hline M14 & 11.3 & 4.4 & 15.5 & 1.7 & 5.0 & 2.2 & 11.3 & 3.9 & 15.3 & 1.6 & 5.8 & 1.7 \\
\hline M17 & 10.1 & 4.2 & 15.2 & 1.6 & 5.5 & 2.1 & 10.4 & 3.9 & 15.3 & 1.6 & 6.5 & 1.6 \\
\hline \multicolumn{13}{|c|}{ YEAR 2 (exceptionally wet) } \\
\hline D1 & 8.6 & 3.0 & 11.6 & 1.0 & 4.8 & 1.7 & 8.2 & 2.7 & 11.1 & 1.1 & 4.9 & 1.8 \\
\hline D6 & 8.9 & 3.6 & 12.6 & 1.3 & 4.5 & 1.7 & 8.8 & 3.5 & 12.4 & 1.4 & 4.6 & 1.8 \\
\hline D10 & 9.2 & 3.6 & 13.0 & 1.5 & 5.0 & 1.4 & 9.3 & 3.4 & 12.9 & 1.5 & 5.2 & 1.3 \\
\hline D12 & - & - & - & - & - & - & - & - & - & - & - & - \\
\hline D16 & 9.6 & 6.5 & 12.2 & 1.2 & 6.4 & 0.9 & 9.2 & 2.1 & 11.3 & 0.9 & 6.6 & 0.8 \\
\hline D17 & 9.2 & 2.4 & 11.6 & 0.9 & 6.3 & 1.0 & 9.2 & 2.3 & 11.6 & 0.9 & 6.4 & 0.9 \\
\hline D20 & 9.9 & 2.6 & 12.2 & 1.1 & 6.2 & 0.9 & 9.8 & 2.4 & 12.0 & 1.0 & 6.3 & 0.8 \\
\hline D23 & 9.5 & 1.9 & 11.4 & 0.7 & 7.1 & 0.8 & 9.4 & 1.8 & 11.3 & 0.7 & 7.2 & 0.8 \\
\hline M2 & 8.8 & 4.3 & 13.4 & 1.7 & 3.2 & 1.8 & 8.4 & 3.9 & 12.8 & 1.5 & 3.6 & 1.8 \\
\hline M8 & 9.3 & 4.5 & 14.2 & 1.9 & 3.6 & 1.8 & 8.9 & 4.1 & 13.4 & 1.7 & 4.2 & 1.8 \\
\hline M11 & 9.3 & 4.7 & 14.2 & 1.9 & 3.7 & 1.8 & 9.0 & 4.3 & 13.5 & 1.6 & 4.3 & 1.9 \\
\hline M12 & - & - & - & - & - & - & - & - & - & - & - & - \\
\hline M14 & 9.7 & 4.7 & 14.6 & 1.7 & 3.5 & 1.8 & 9.6 & 4.5 & 14.5 & 1.8 & 4.2 & 1.9 \\
\hline M17 & 9.5 & 4.4 & 14.2 & 1.7 & 3.7 & 2.0 & 9.6 & 4.3 & 14.2 & 1.6 & 4.3 & 2.0 \\
\hline
\end{tabular}


Table 3 Cross-calibration and validation of logistic regression and delta models at selected sites, showing amount of explained variance $\left(r^{2}\right)$ and standard error (SE) in each case.

\begin{tabular}{|c|c|c|c|c|c|c|c|c|c|c|c|}
\hline \multirow{2}{*}{ Model } & \multirow[t]{2}{*}{ Site } & \multicolumn{2}{|c|}{ D11 } & \multicolumn{2}{|c|}{ D16 } & \multicolumn{2}{|c|}{ D23 } & \multicolumn{2}{|c|}{ M2 } & \multicolumn{2}{|c|}{ M14 } \\
\hline & & $\mathbf{r}^{2}$ & SE & $\mathbf{r}^{2}$ & $\mathrm{SE}$ & $\mathbf{r}^{2}$ & SE & $\mathbf{r}^{2}$ & SE & $\mathbf{r}^{2}$ & SE \\
\hline \multirow{4}{*}{$\mathrm{dTw}$} & Calibration Yr 1 & 0.94 & 0.05 & 0.92 & 0.05 & 0.89 & 0.04 & 0.92 & 0.06 & 0.90 & 0.08 \\
\hline & Validation Yr 2 & 0.83 & 0.08 & 0.82 & 0.08 & 0.82 & 0.05 & 0.90 & 0.07 & 0.89 & 0.08 \\
\hline & Cal & 0.83 & 0.08 & 0.82 & 0.05 & 0.83 & 0.04 & 0.90 & 0.07 & 0.89 & 0.08 \\
\hline & Validation Yr 1 & 0.94 & 0.05 & 0.91 & 0.08 & 0.88 & 0.04 & 0.92 & 0.06 & 0.90 & 0.08 \\
\hline \multirow{4}{*}{ nTw } & Calibration Yr 1 & 0.92 & 0.05 & 0.90 & 0.05 & 0.87 & 0.04 & 0.83 & 0.06 & 0.83 & 0.10 \\
\hline & Validation Yr 2 & 0.83 & 0.08 & 0.82 & 0.07 & 0.80 & 0.04 & 0.83 & 0.08 & 0.83 & 0.09 \\
\hline & Calib & 0.83 & 0.08 & 0.80 & 0.05 & 0.82 & 0.04 & 0.83 & 0.08 & 0.83 & 0.09 \\
\hline & Validation Yr 1 & 0.91 & 0.05 & 0.86 & 0.08 & 0.85 & 0.04 & 0.83 & 0.09 & 0.83 & 0.10 \\
\hline \multirow{4}{*}{ Delta } & Calibra & 0.92 & 0.05 & 0.90 & 0.05 & 0.87 & 0.04 & 0.84 & 0.06 & 0.84 & 0.10 \\
\hline & Validation Yr 2 & 0.83 & 0.08 & 0.82 & 0.07 & 0.81 & 0.04 & 0.84 & 0.08 & 0.84 & 0.09 \\
\hline & Calibration Yr 2 & 0.83 & 0.08 & 0.82 & 0.05 & 0.82 & 0.04 & 0.84 & 0.08 & 0.84 & 0.09 \\
\hline & Validation Yr 1 & 0.92 & 0.05 & 0.90 & 0.08 & 0.85 & 0.04 & 0.84 & 0.09 & 0.84 & 0.10 \\
\hline
\end{tabular}




\section{FIGURES}

Figure 1 Dove and Manifold catchments showing LUTEN monitoring sites (red circles), EA gauging stations (black circles), limestone outcrop (grey shading), sandstone, and mudstone areas (un-shaded).

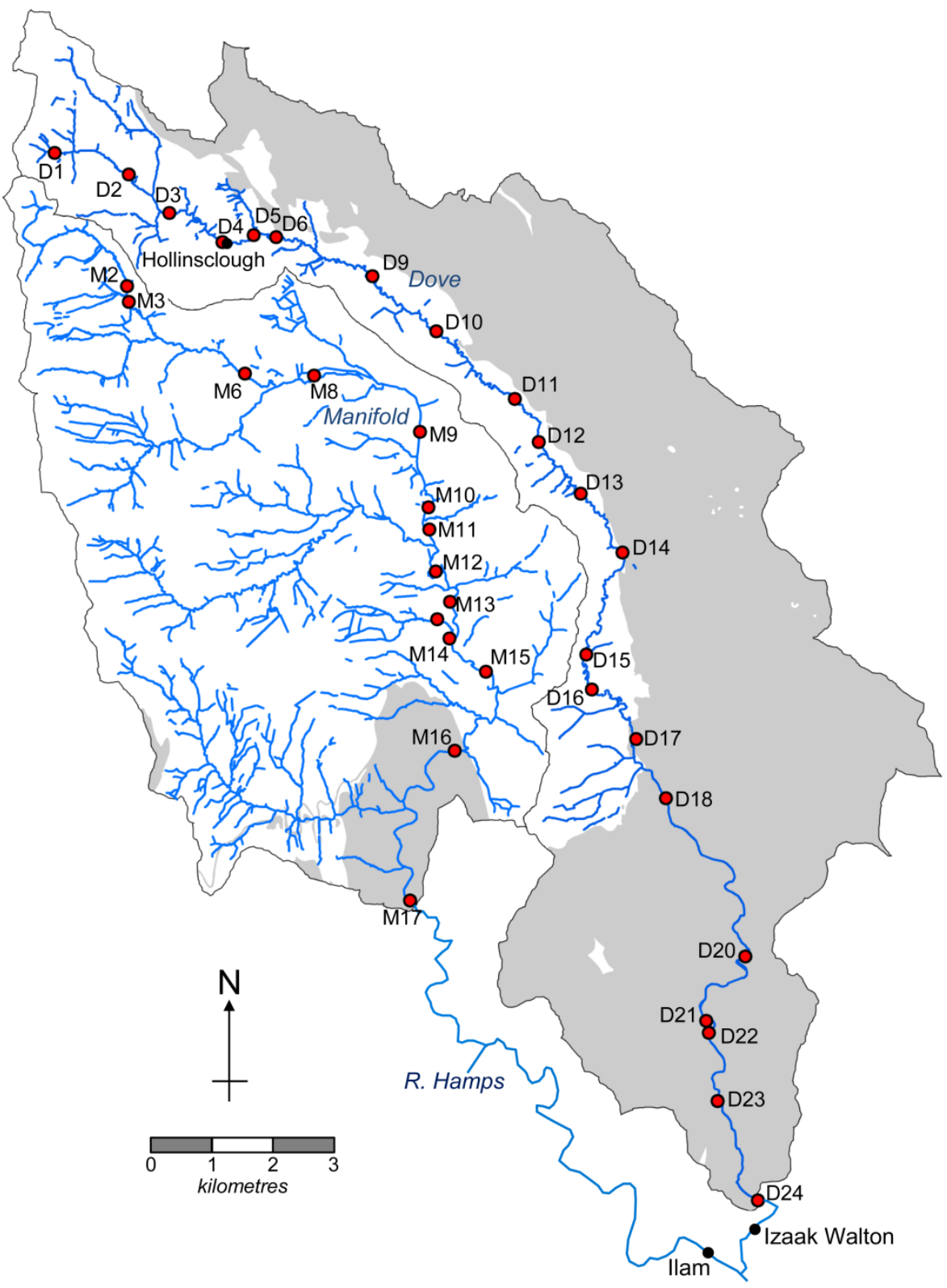


Figure 2 Example of an anti-clockwise hysteresis loop for paired Tw and Ta at site D11 beginning 12:00 pm on 11 July 2011 and ending 11:45 am on 12 July 2011. Open circles are daylight measurements; closed circles are nocturnal measurements. Maximum and minimum values are highlighted by dashed lines.

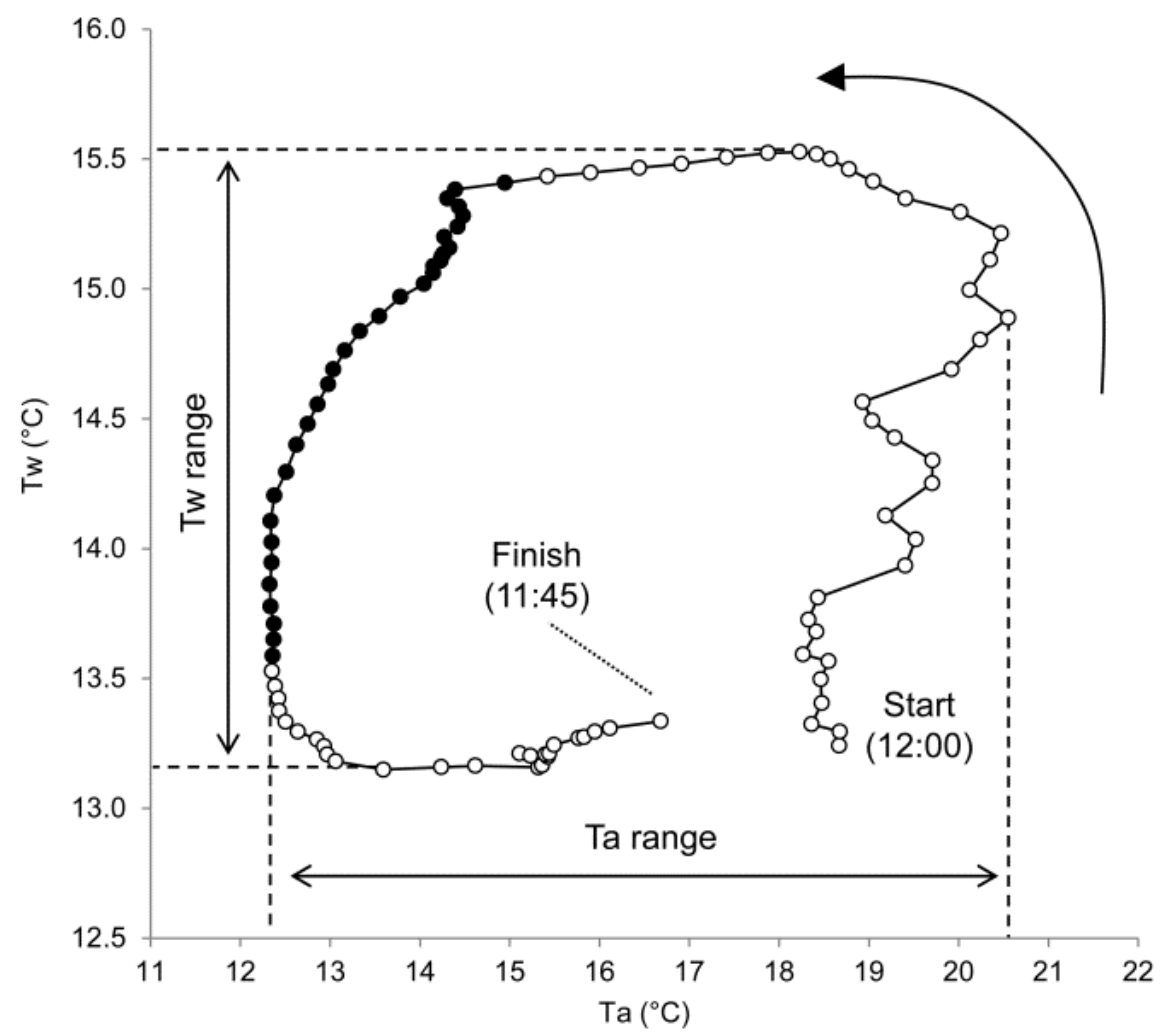


Figure 3 Monthly mean water temperature range during day (dTw, left) and night (nTw, right) at selected sites in the Dove from March 2011 to February 2012; a, b) D2; c, d) D10; e, f) D16; g, h) D23. T-bars show the full range between maximum and minimum.
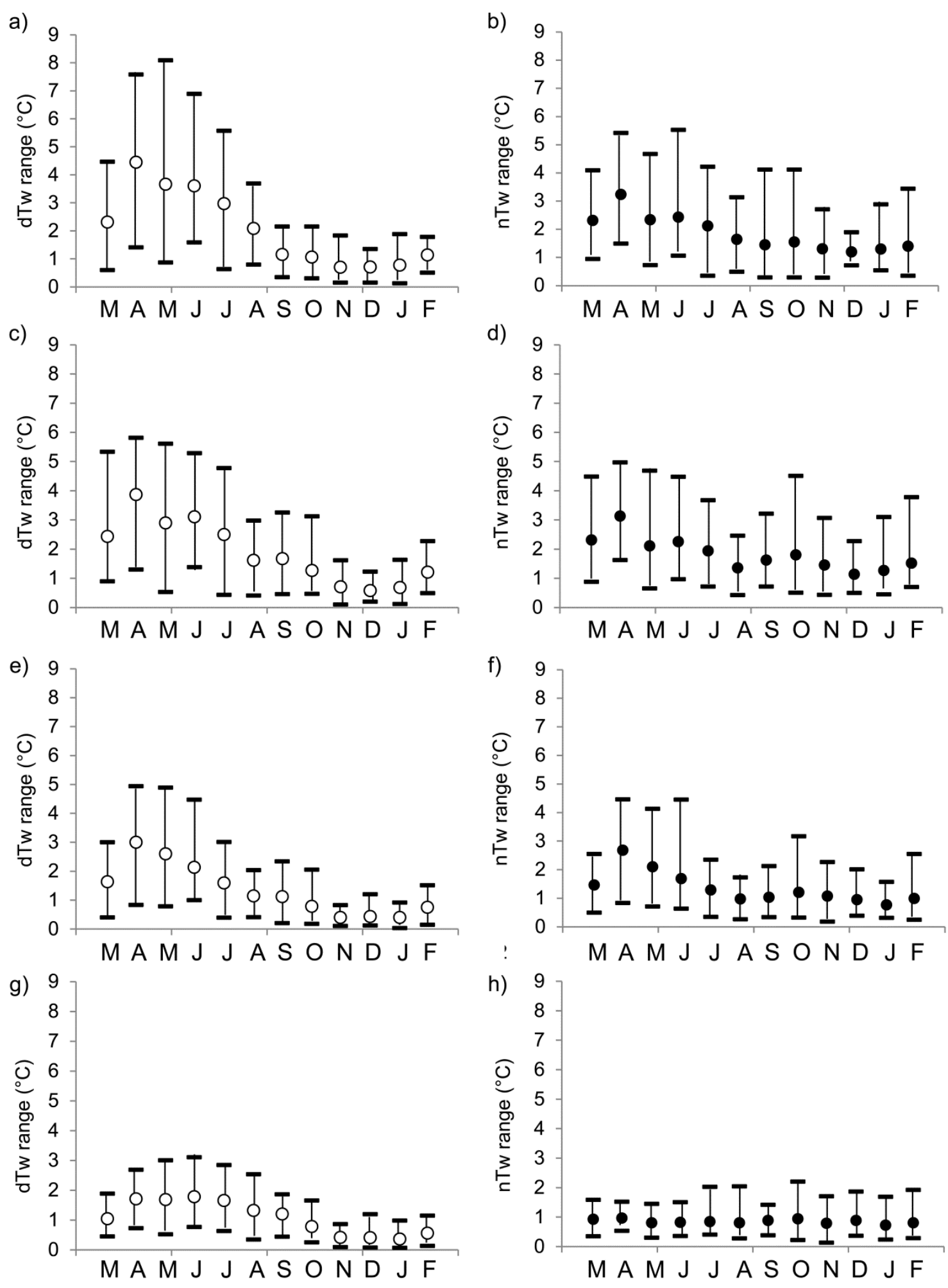
Figure 4 Diel range in Tw versus discharge at D11 for both years during a) summer half year (April to September) and b) winter half year (October to March). Note that the two outliers in a) coincided with snow melt in April.
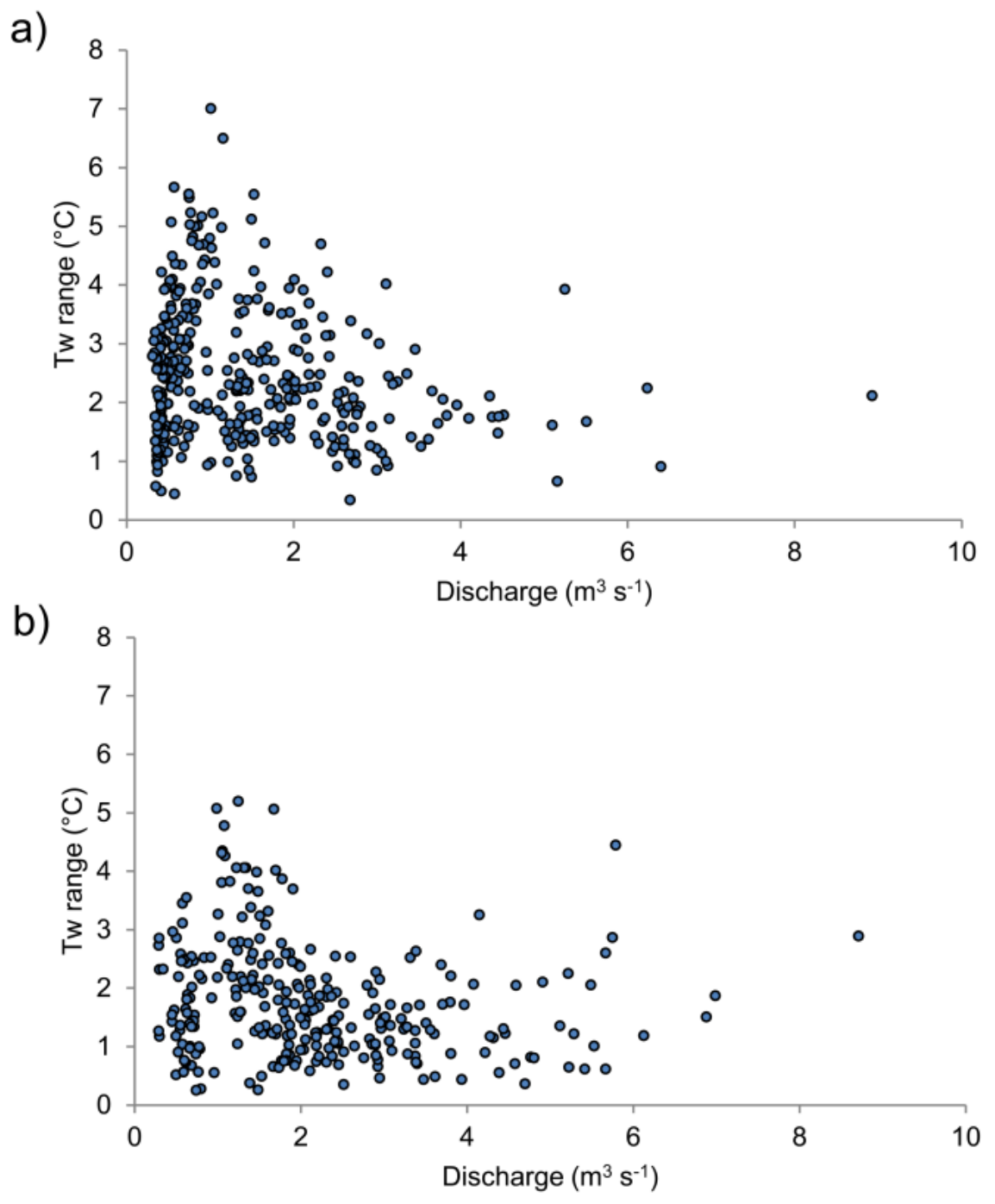
Figure 5 Time-lag between daily maximum Ta and Tw for sites in the Dove during a) Year 1 and b) Year 2. Boxes denote one standard deviation about the mean; whiskers show the full range. The sample only includes days with anti-clockwise hysteresis.

a)

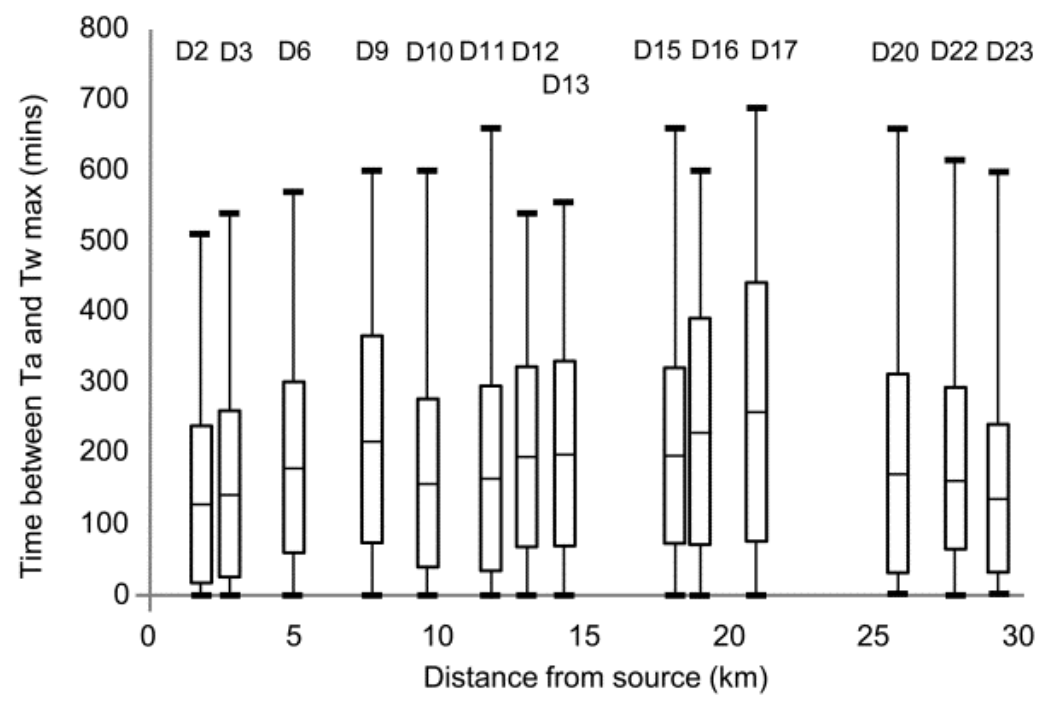

b)

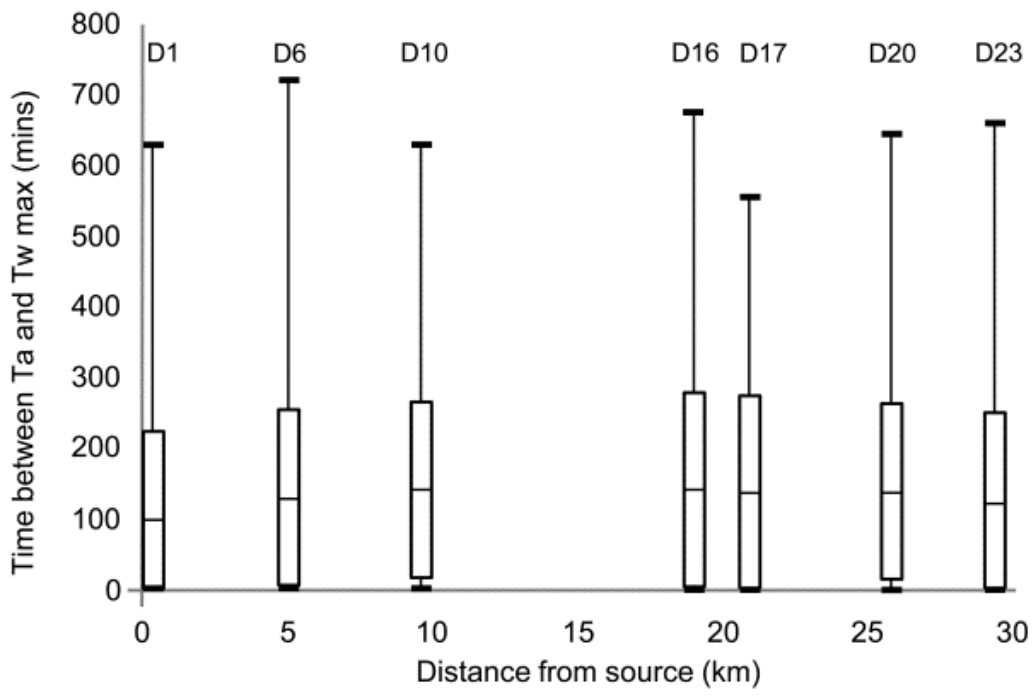


Figure 6 Thermal waves produced by the storm of 28 June 2012 showing: 15 minute Tw variation at selected sites in a) the Dove and b) Manifold; c) 15 minute Ta variation at sites D11 and M8; d) travel time of the Tw peak to all sites above D23.
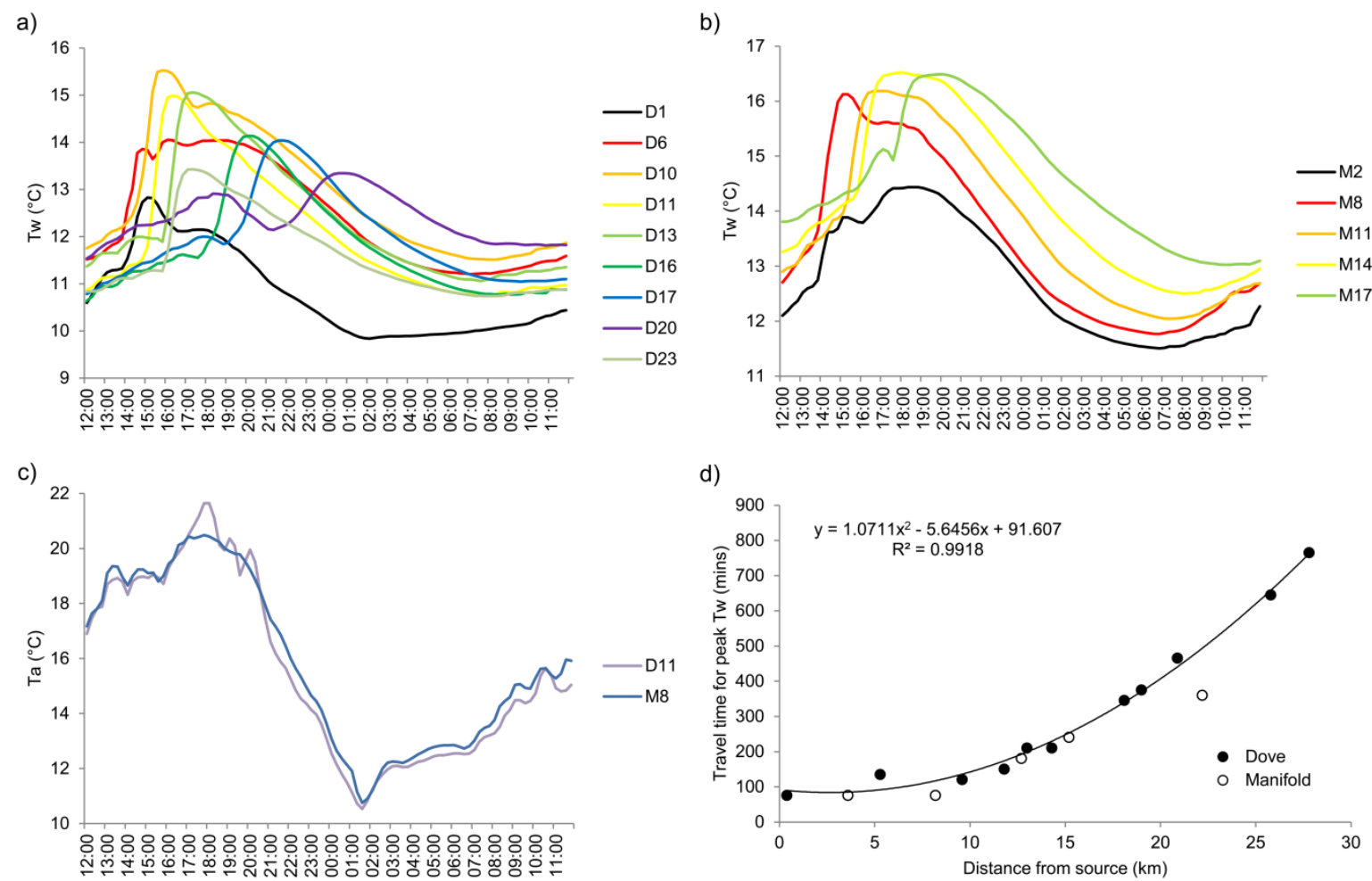
Figure 7 a) Hysteresis loops on 26 June 2011 for sites in the Dove with distance from source (zones of groundwater influence are shown in blue; grey shading discriminates sites above major springs); b) longitudinal profile of the Dove showing monitoring sites and extent of groundwater.

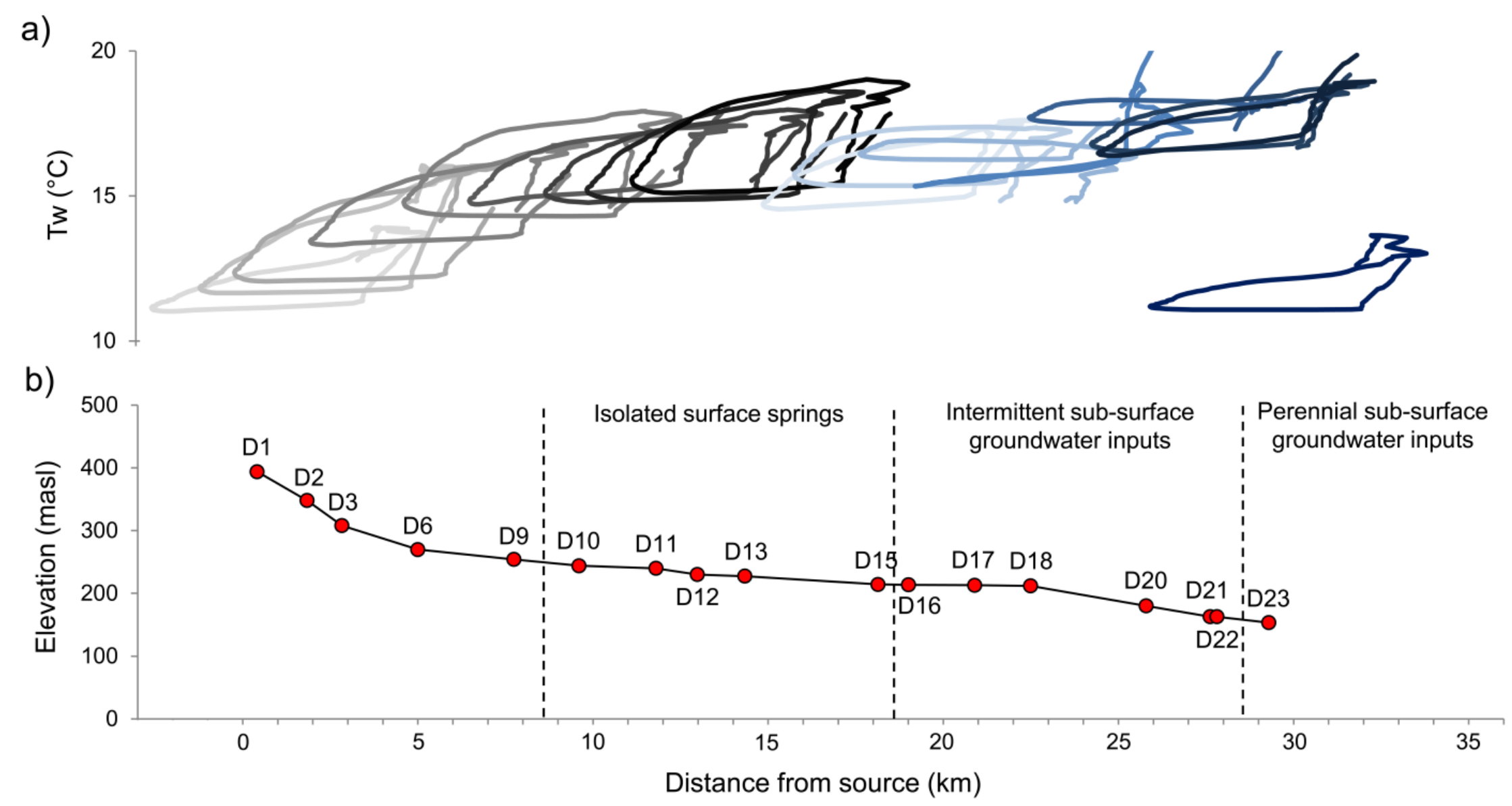


Figure 8 Hysteresis loops for D1 (left) and D11 (right) on selected low flow days: a, b) 26 June $2011\left(\mathrm{Q}=0.58 \mathrm{~m}^{3} \mathrm{~s}^{-1}\right)$; c, d) 11 July $2011\left(\mathrm{Q}=0.40 \mathrm{~m}^{3} \mathrm{~s}^{-1}\right)$; and e, f) 7 September 2011 $\left(\mathrm{Q}=0.40 \mathrm{~m}^{3} \mathrm{~s}^{-1}\right)$

a)

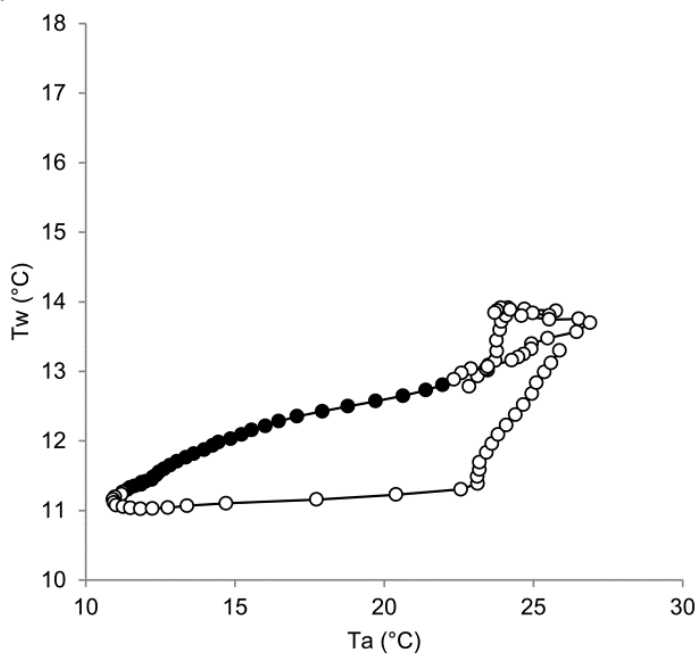

c)

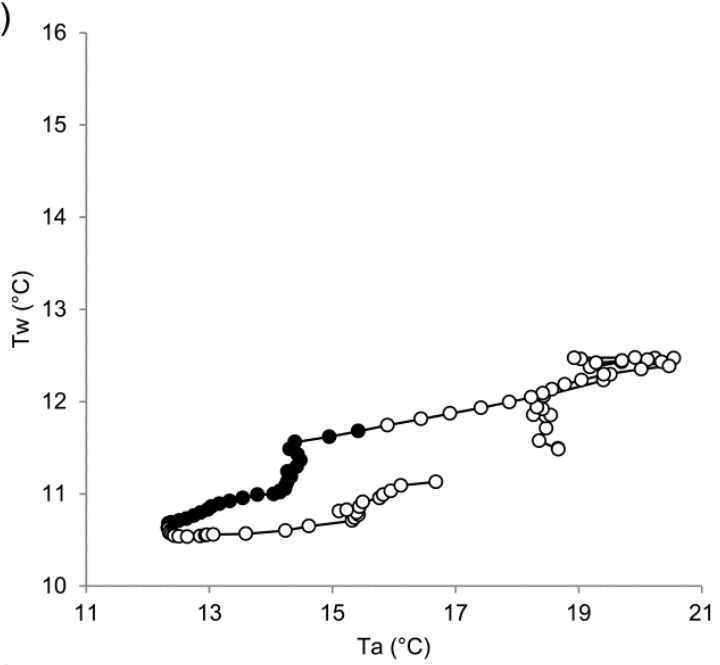

e)

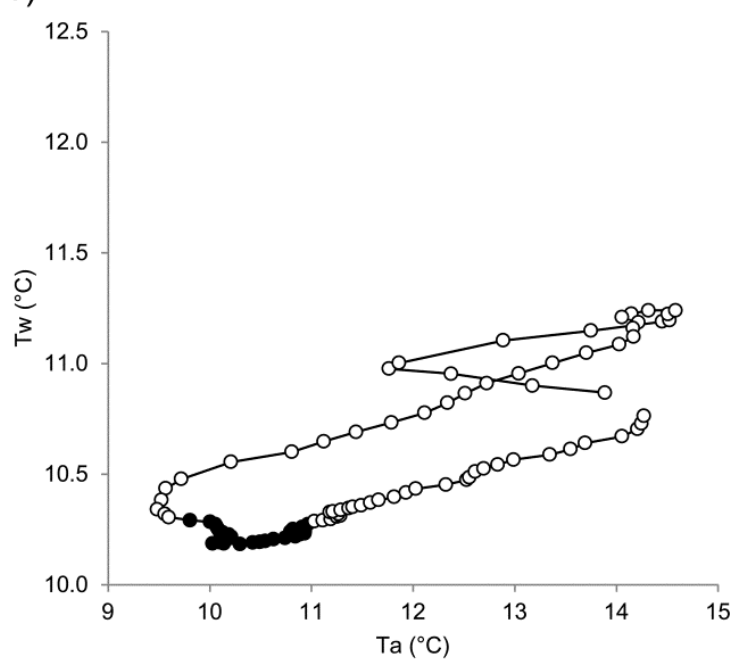

b)

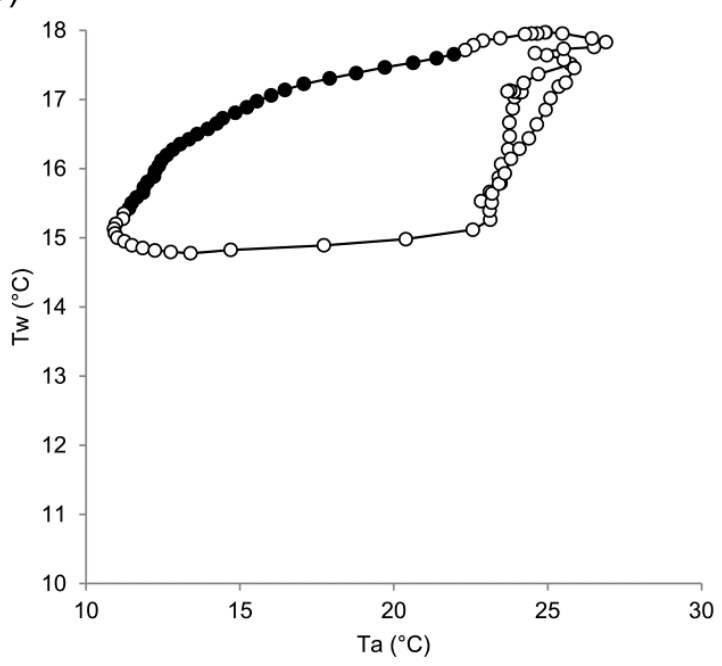

d)

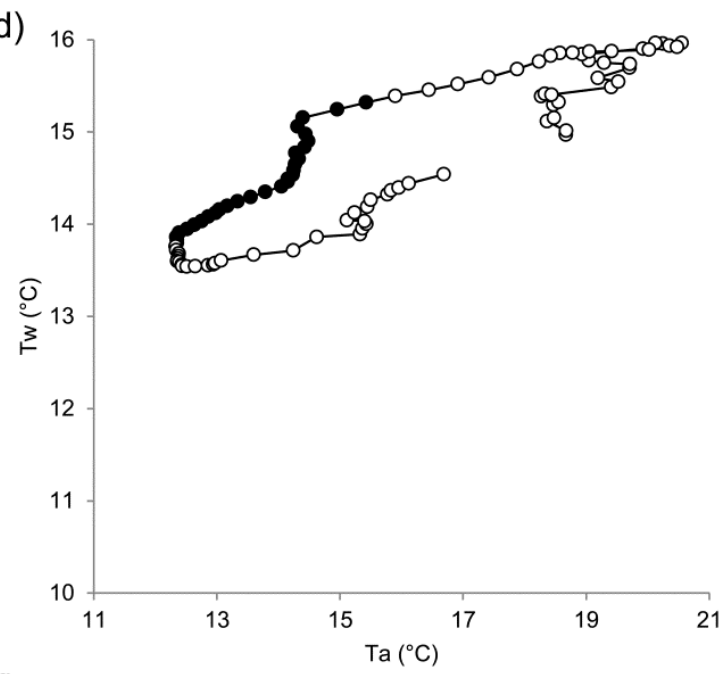

f)

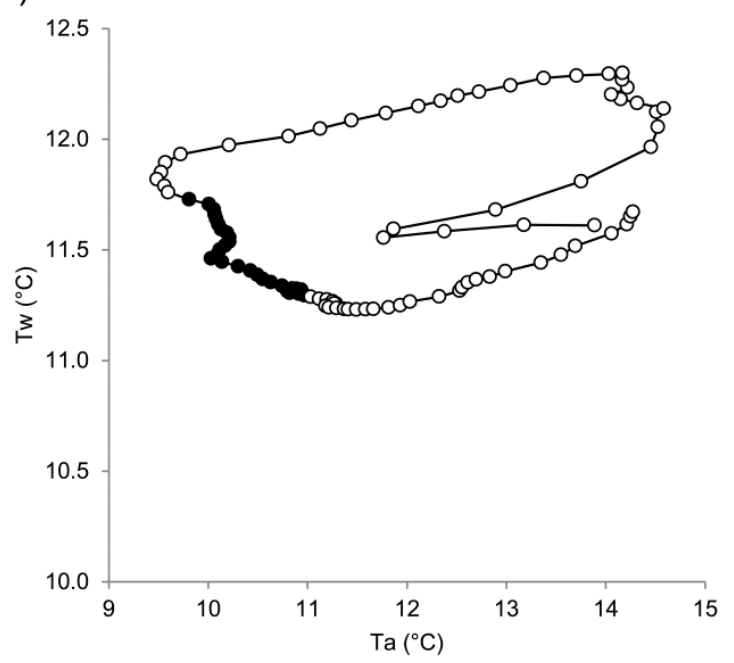


Figure 9 Hysteresis loops for D1 (left) and D10 (right) on selected high flow days: a, b) 8 June $2012\left(\mathrm{Q}=8.93 \mathrm{~m}^{3} \mathrm{~s}^{-1}\right)$; c, d) 22 June $2012\left(\mathrm{Q}=4.38 \mathrm{~m}^{3} \mathrm{~s}^{-1}\right)$; and e, f) 28 June $2012(\mathrm{Q}=$ $\left.3.11 \mathrm{~m}^{3} \mathrm{~s}^{-1}\right)$

a)

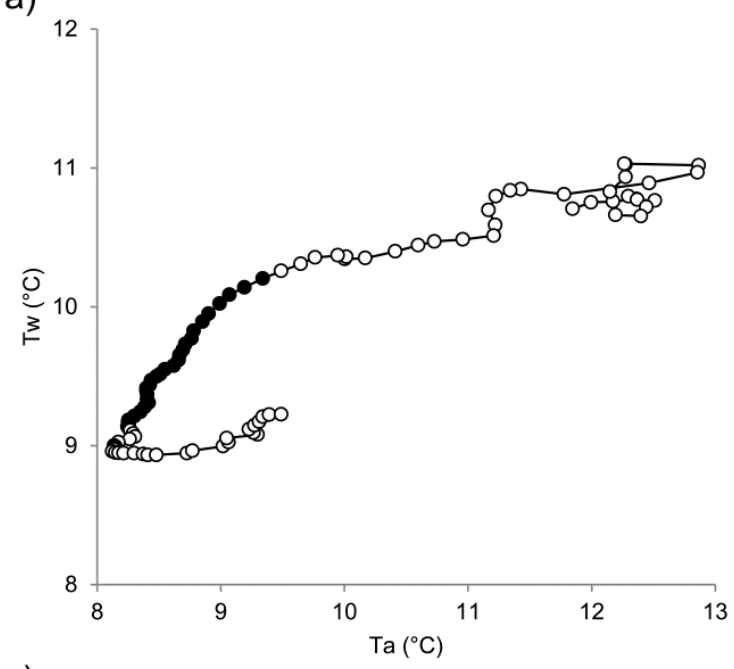

c)

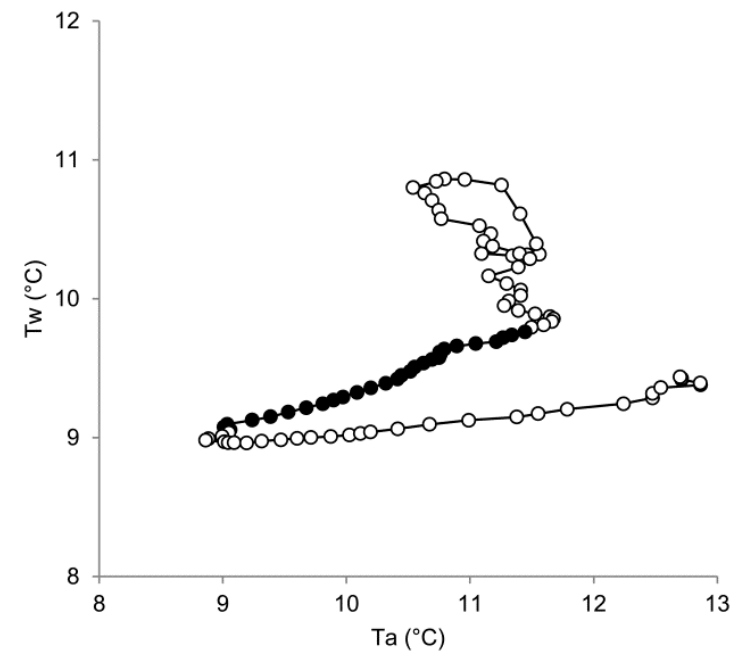

e)

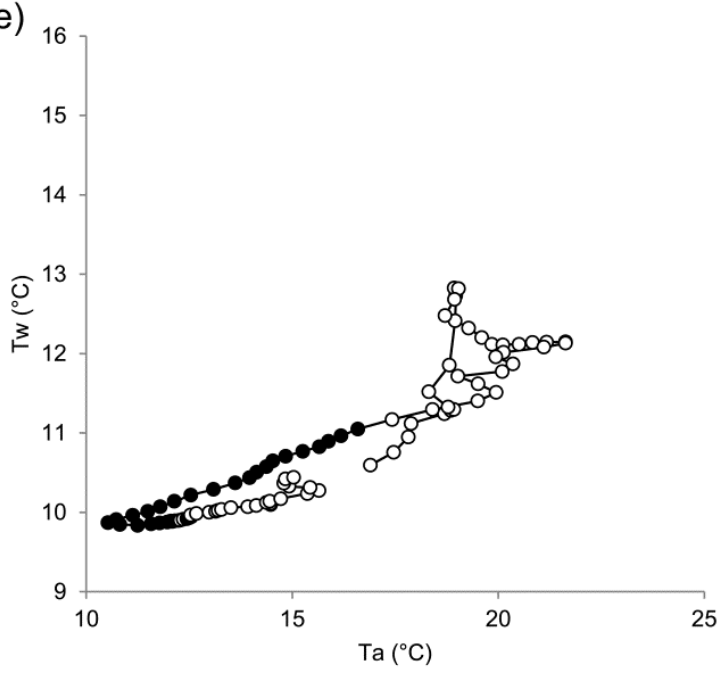

b)

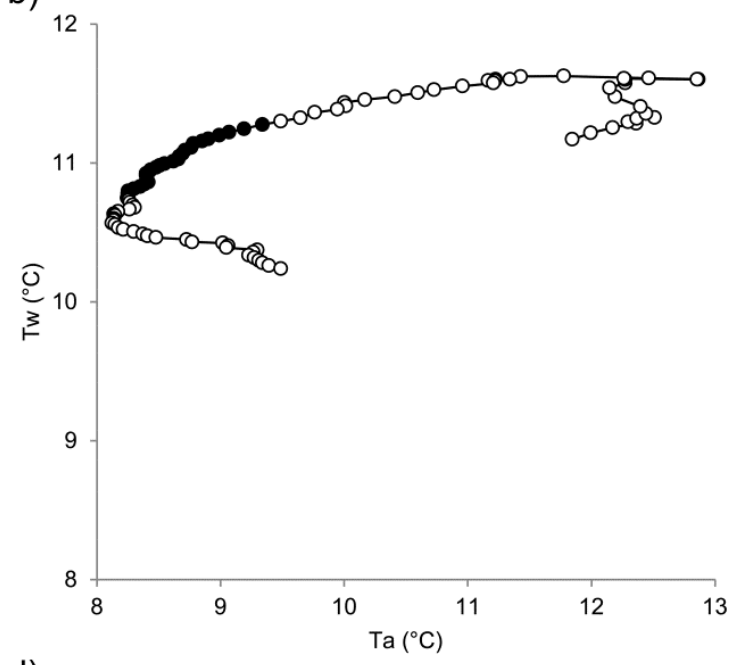

d)

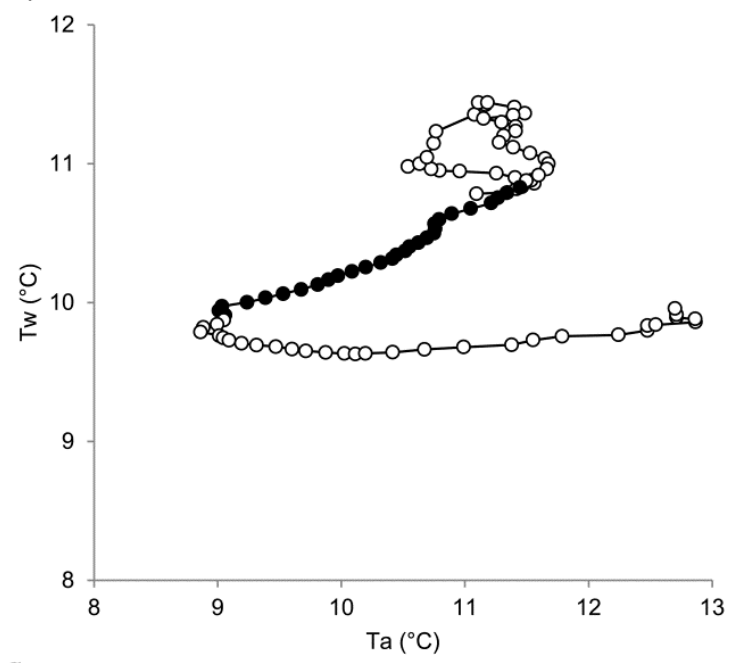

f)

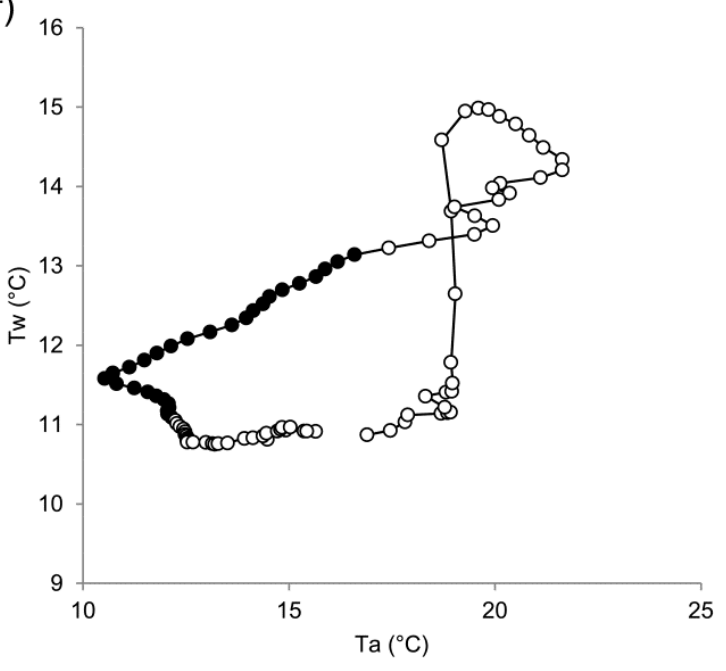


Figure 10 Correlation of a) Tw versus lagged Ta maxima and b) Tw versus lagged Tw maxima for sites in the Dove. Day is red, night is blue, Year 1 is solid and Year 2 is dashed lines.
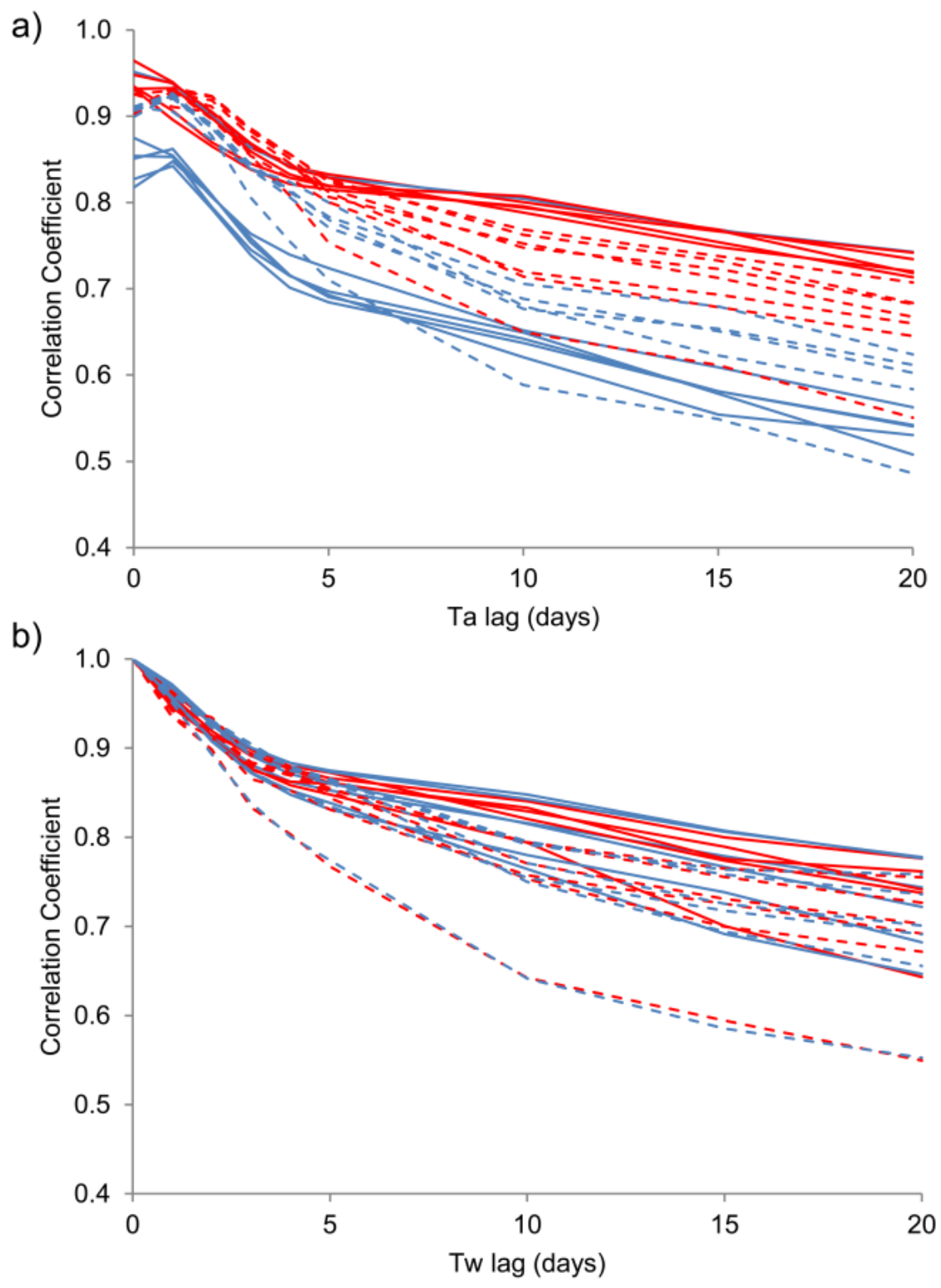
Figure 11 Downstream and seasonal variations in the $\delta$ factor for daily maximum nTw in the Dove during (a) Year 1 and (b) Year 2. Summer is defined as June to August and winter is December to February.

a)

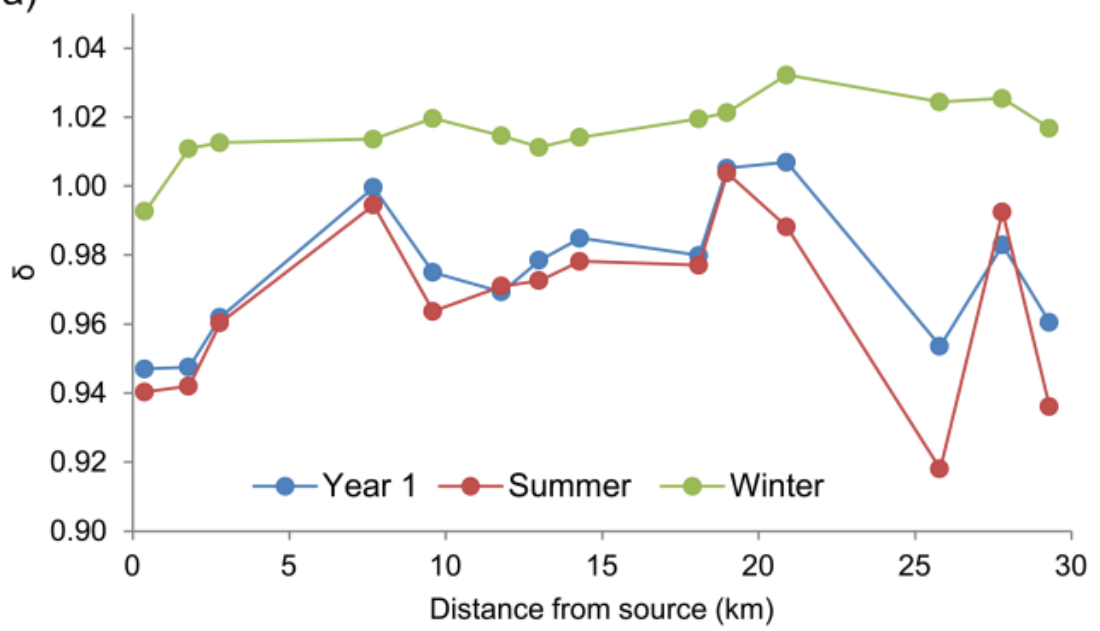

b)

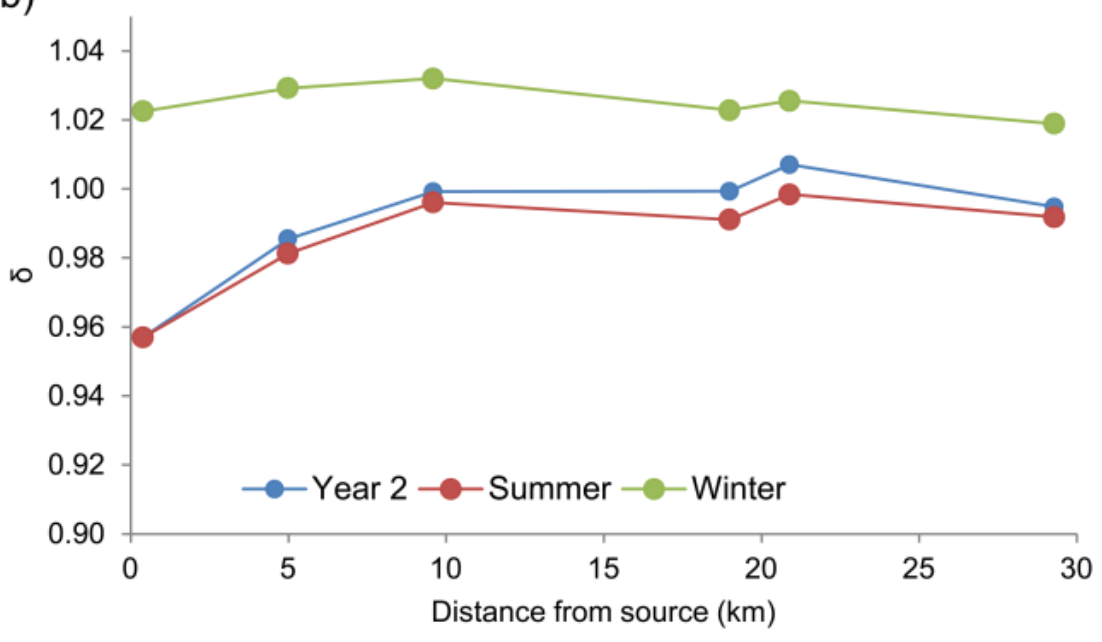


Figure 12 Logistic regression models of dTw based on dTa (solid black line), nTw estimated from dTa (black dashed line), and nTw estimated from dTw (red dashed line) at site D11 in (a) Year 1 and (b) Year 2. Open circles denote observed dTw, grey circles nTw.
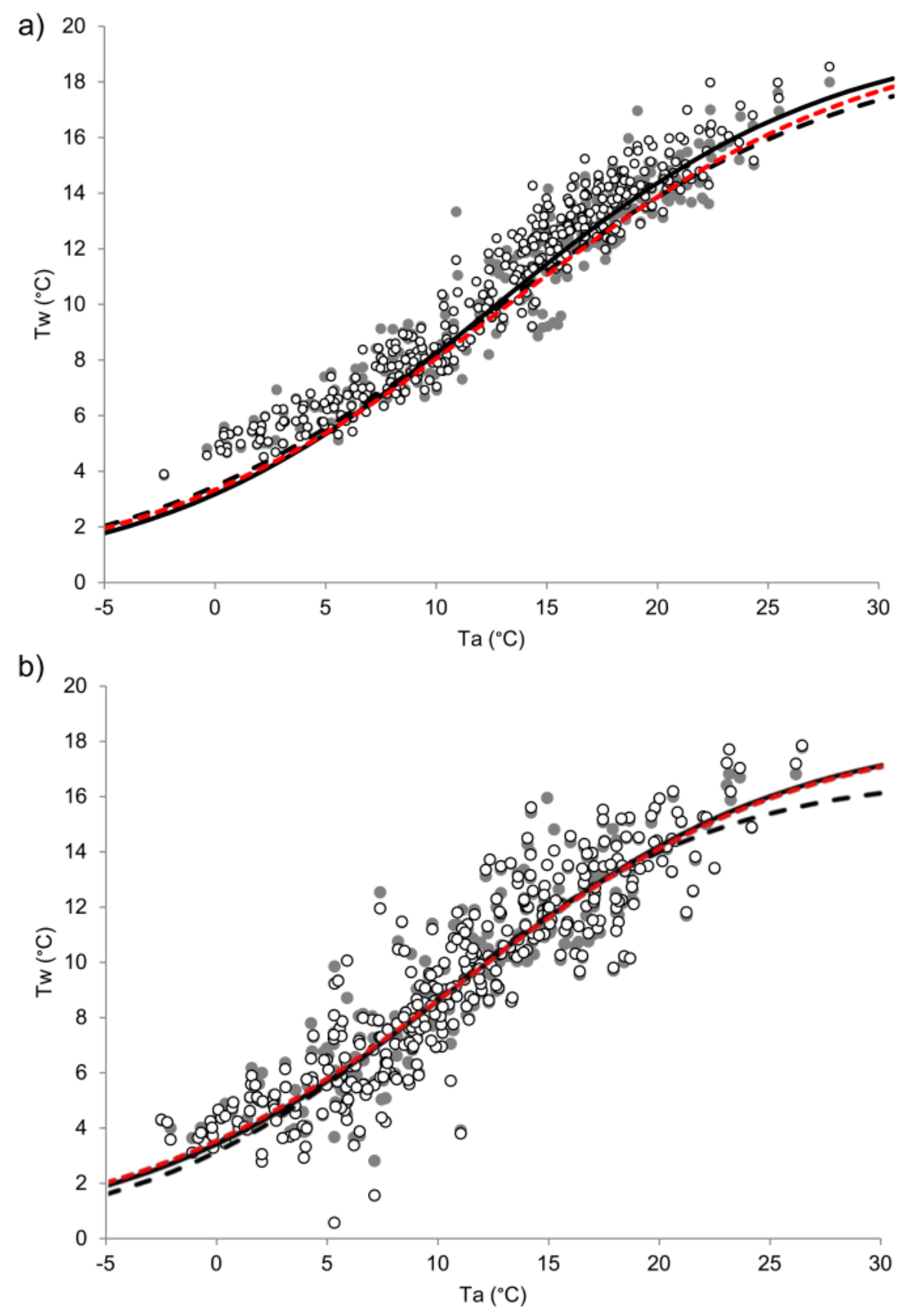
Figure 13 Model residuals (grey line) for nTw estimated from dTw at site D11 with daily discharge shown for Izaak Walton (blue line).

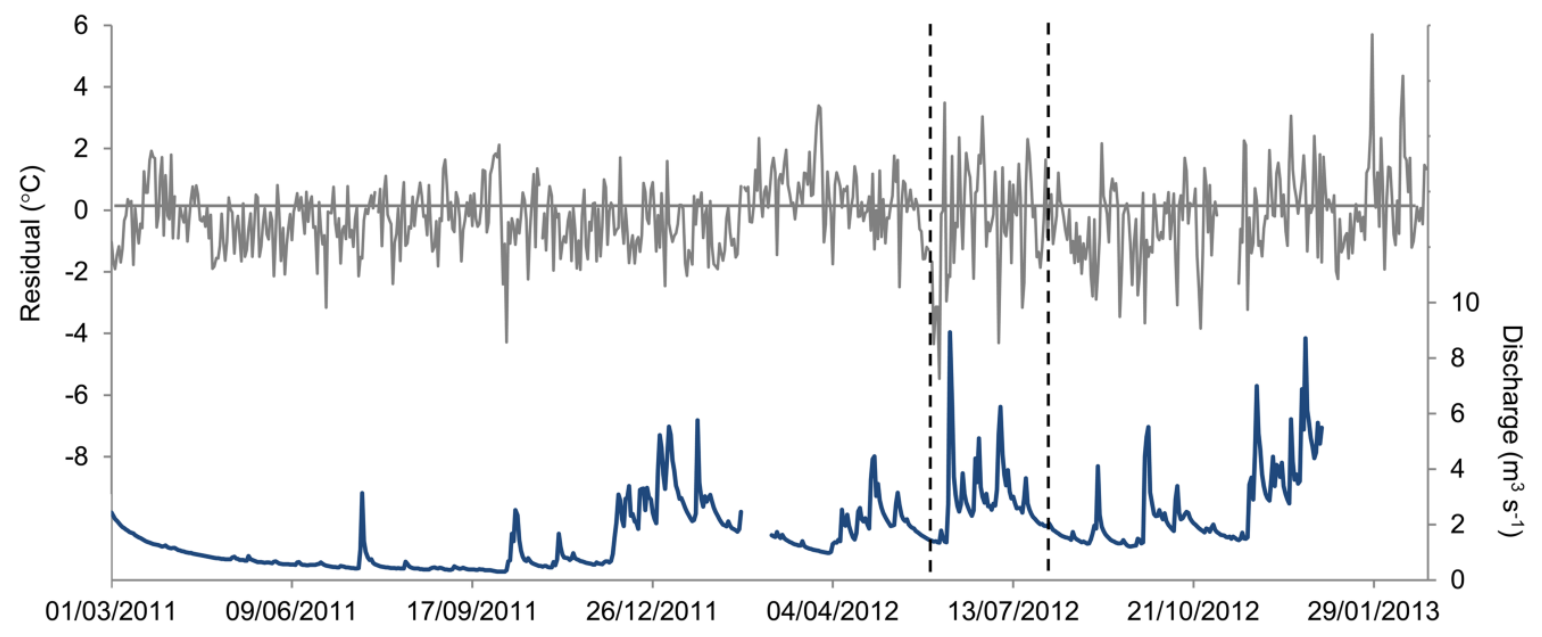


Figure 14 Discharge versus regression model residuals for dTw (left) and nTw (right) at selected sites in the Dove for models calibrated on both years at sites a, b) D1; c, d) D11 and; e, f) D16.

a)

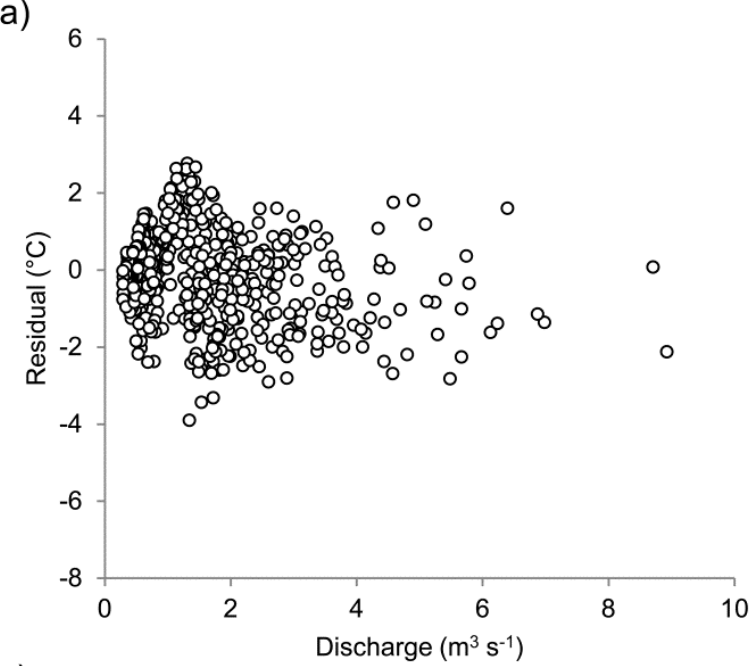

c)

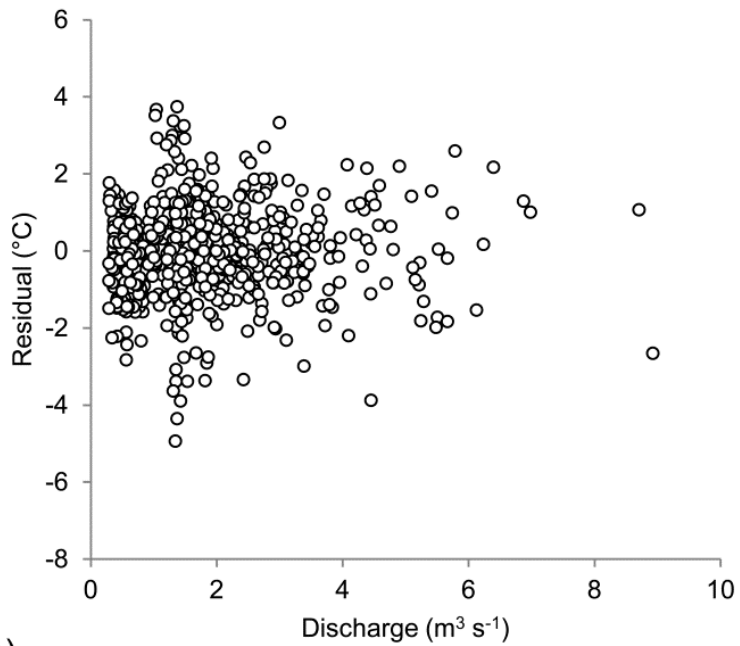

e)

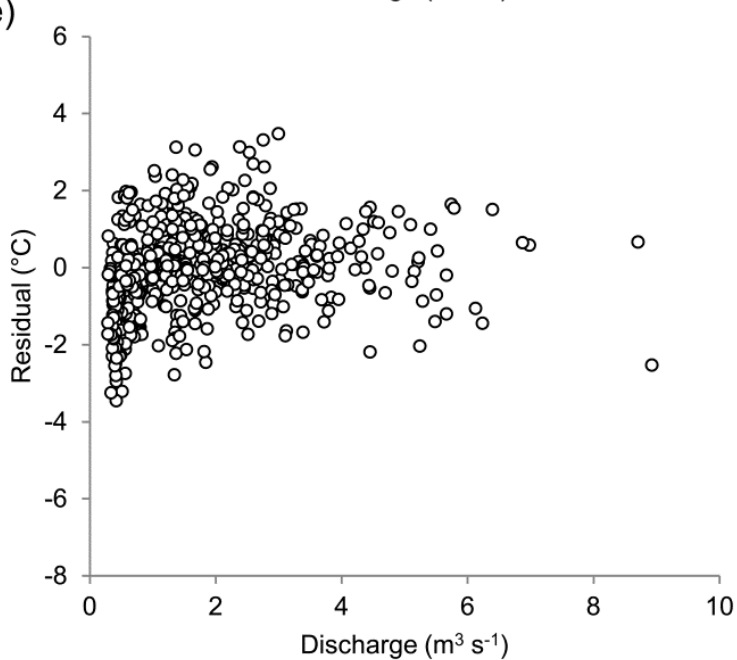

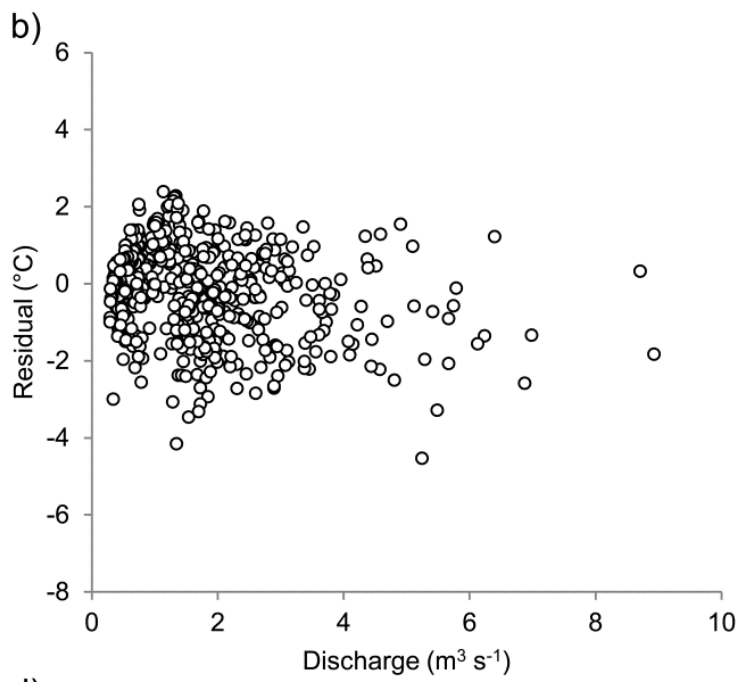

d)
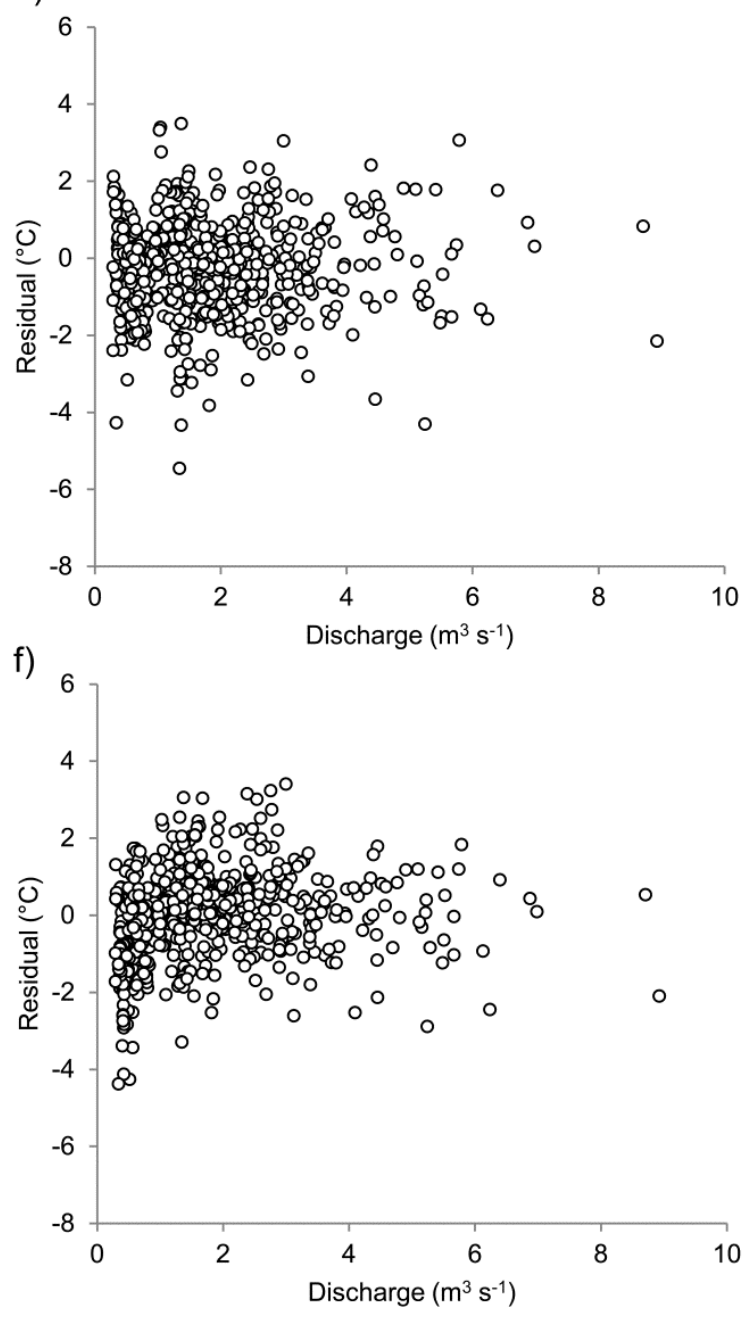
Figure 15 Logistic regression parameters for dTw with distance from source of the Dove (left) and Manifold (right) during Year 1 (blue) and Year 2 (red). T-bars show standard errors.
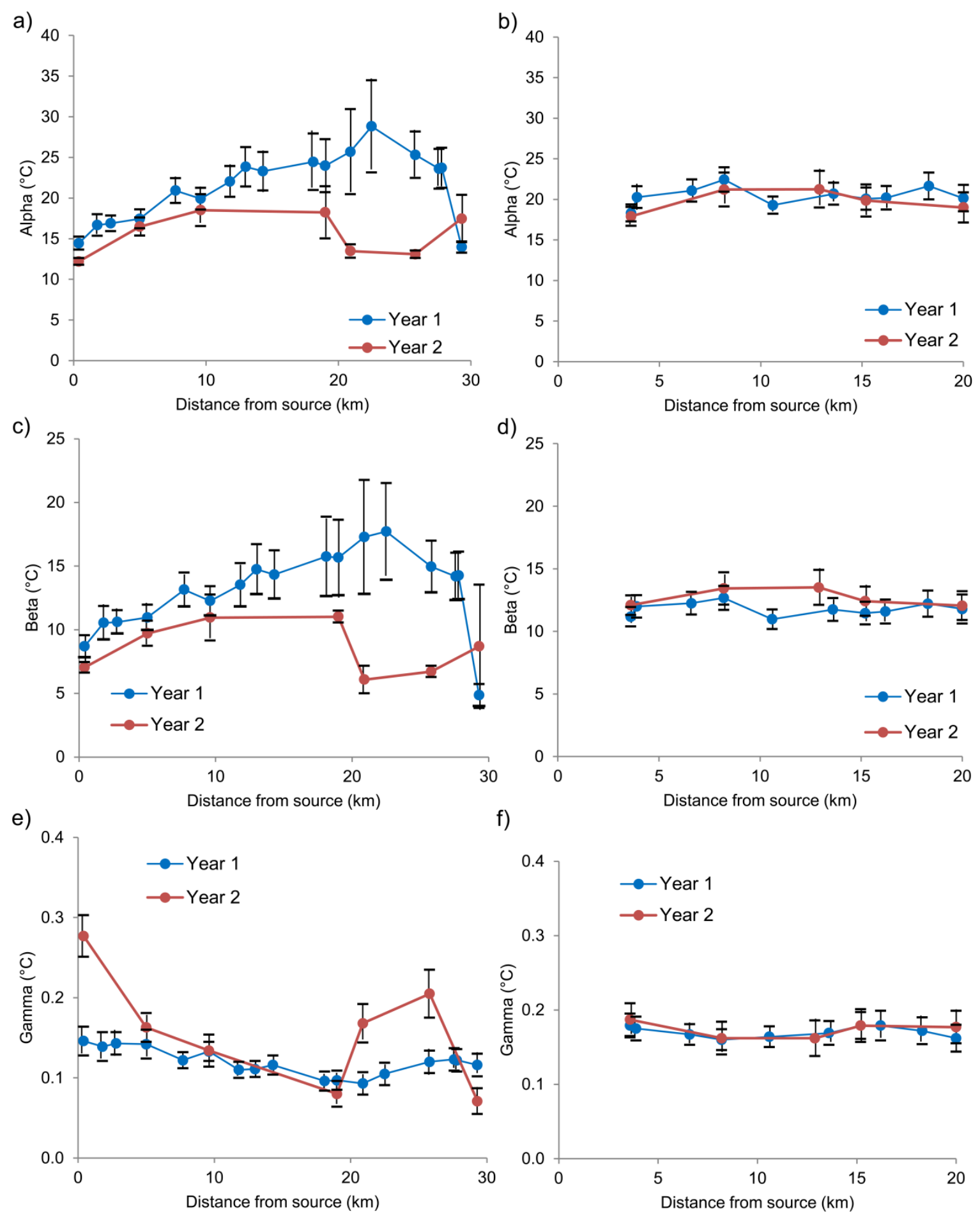


\section{SUPPLEMENTARY FIGURES}

Figure S1 Downstream and seasonal variations in the $\delta$ factor for daily minimum nTw in the Dove during Year 1.

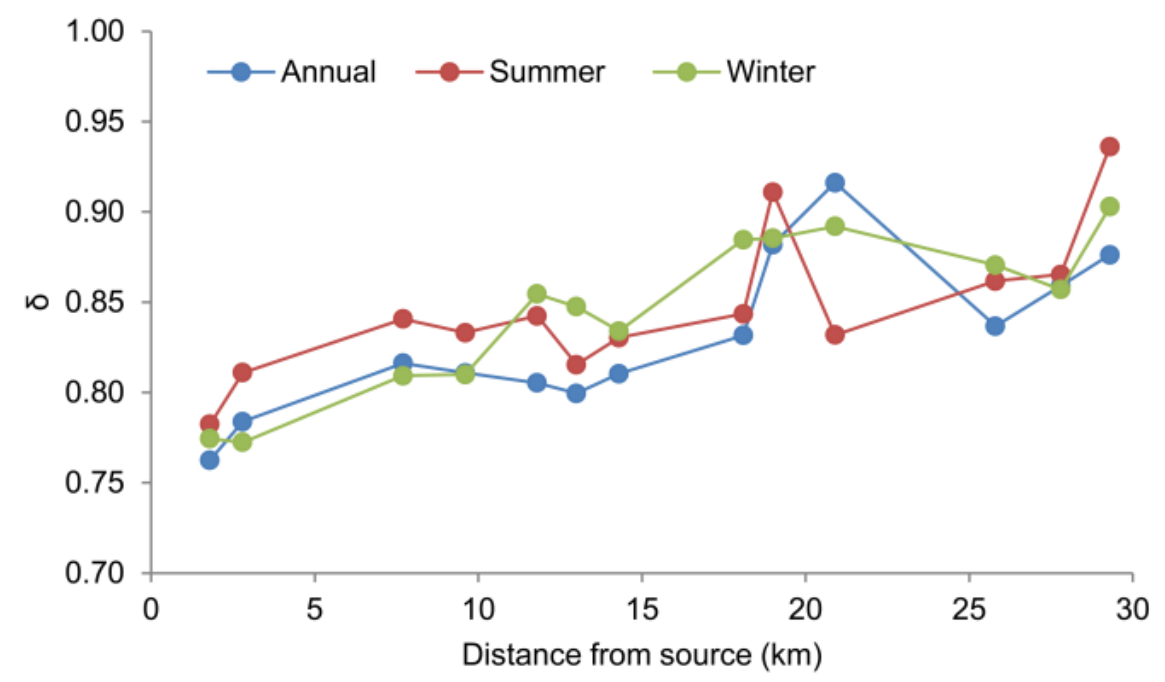


Figure S2 Amount of explained variance $\left(\mathrm{R}^{2}\right)$ in dTw and nTw maxima as a function of dTa with distance downstream in the Dove (upper panel) and Manifold (lower panel) in Year 1.
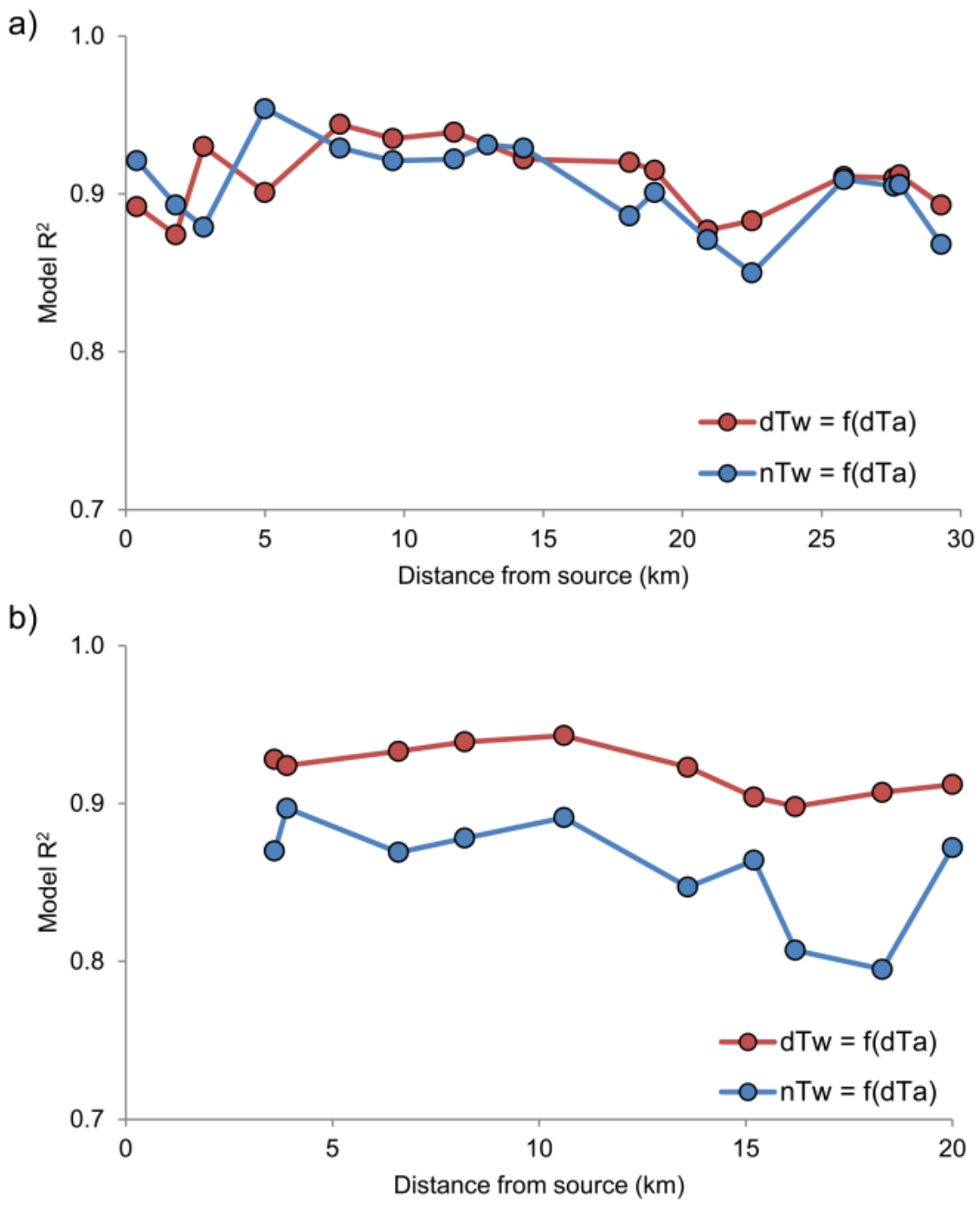
Figure S3 Logistic model estimates of maximum dTw for a) partly ( $<10 \%)$ shaded (D17) and b) heavily (>80\%) shaded (D10) sites during dry (Year 1) and wet (Year 2) weather.

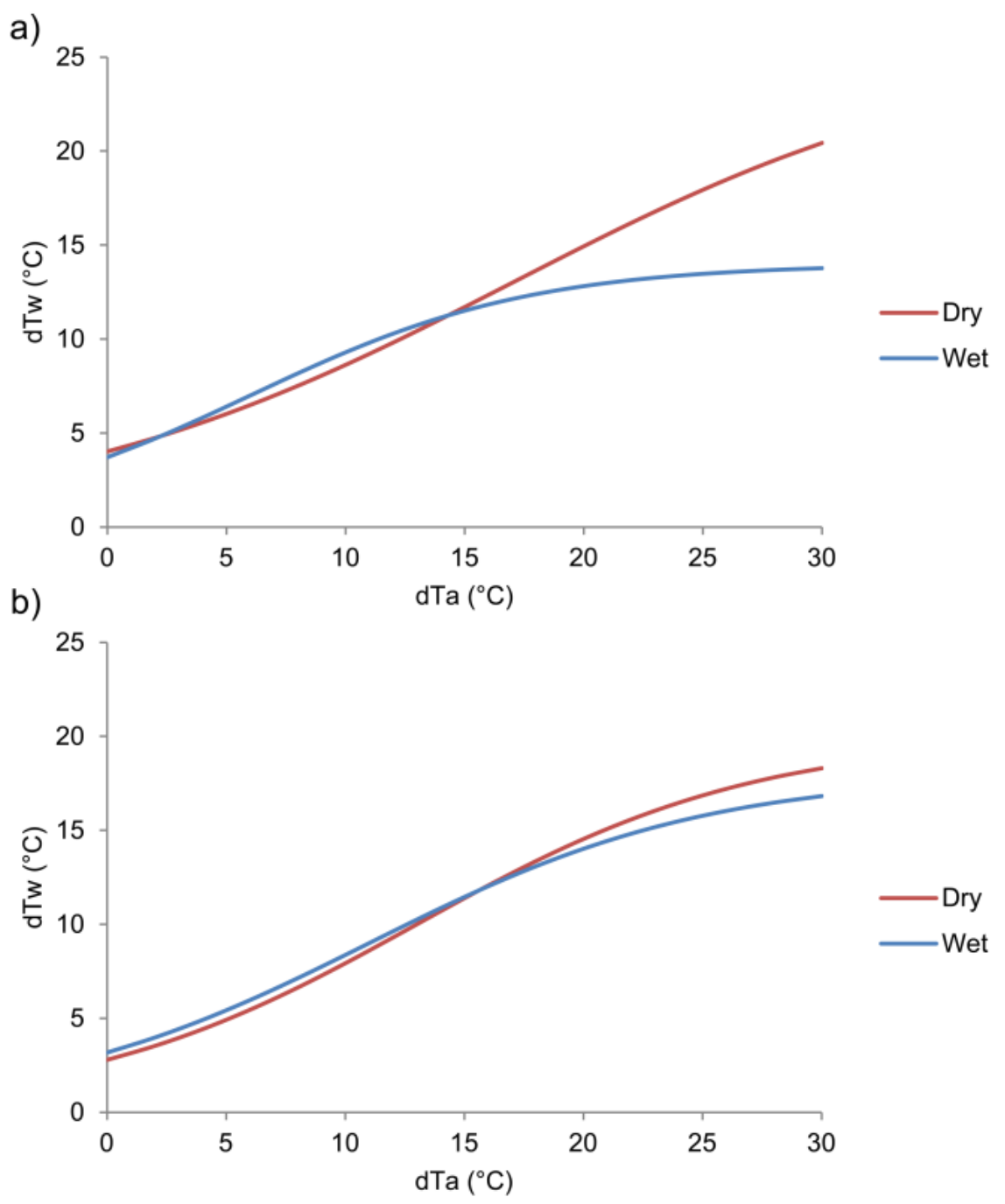

